\title{
Pressure Analysis of the Hydromechanical Fracture Behaviour in Stimulated Tight Sedimentary Geothermal Reservoirs
}

\author{
S. Wessling ${ }^{a}{ }^{\star}$, R. Junker ${ }^{\mathrm{a}}$, J. Rutqvist ${ }^{\mathrm{b}}$, D. Silin ${ }^{\mathrm{b}}$, H. Sulzbacher ${ }^{\mathrm{a}}$, T. Tischner ${ }^{\mathrm{c}}$, C.-F. \\ Tsang ${ }^{\mathrm{b}}$ \\ ${ }^{a}$ Leibniz Institute for Applied Geosciences, Stilleweg 2, D-30655 Hannover, \\ Germany \\ ${ }^{\mathrm{b}}$ Lawrence Berkeley National Laboratory, Earth Sciences Division, MS 90-1116, \\ Berkeley, CA, 94720 USA \\ ${ }^{c}$ Federal Institute for Geosciences and Natural Resources, Stilleweg 2, D-30655 \\ Hannover, Germany
}

\begin{abstract}
Hydromechanical phenomena in fractured sediments are complex. They control the flow in stimulated tight sediments and are crucial for the exploitation of geothermal energy from such rocks. We present the analysis of a cyclic water injection/production (huff-puff) process, a promising method to extract geothermal energy from tight sedimentary reservoirs. It uses a single borehole, which considerably reduces investment costs. A huff-puff test was performed in a 3800-m deep sedimentary formation (borehole Horstberg Z1, Lower Saxony, Germany). The analysis presented herein explains the downhole pressure measurements by a simplified reservoir model containing a single vertical fracture. The model addresses the flow behaviour between the fracture and the rock matrix in a layered formation, and the coupling between fluid flow and the mechanical deformation of the fracture. The latter aspect is relevant to predict the efficiency of the geothermal reservoir because cooled regions resulting from a particular injection/production scheme can be identified. The analysis methods include, 1) the curvefitting code ODA used for a determination of different flow regimes (radial or linear), 2) an analytical solution for the calculation of the injection pressure, assuming a time-dependent fracture area, and 3) the simulator ROCMAS, which numerically solves the coupling between fluid flow and fracture deformation. Whereas each single approach is insufficient to explain the complete test data, a combination of the results yields an understanding of the flow regimes taking place during the test.
\end{abstract}

\footnotetext{
* Corresponding author: Tel.: +49 5141203 6739; fax: +49 5141203362 (now with Baker \& Hughes INTEQ)

E-mail address: Stefan.Wessling@inteq.com (S. Wessling)
} 
Keywords: Geothermal; Enhanced Geothermal Systems; Huff-puff process; Pressure transients; Tight sediments; Hydromechanical effects; Fracture flow; Flow regimes

\section{Nomenclature}

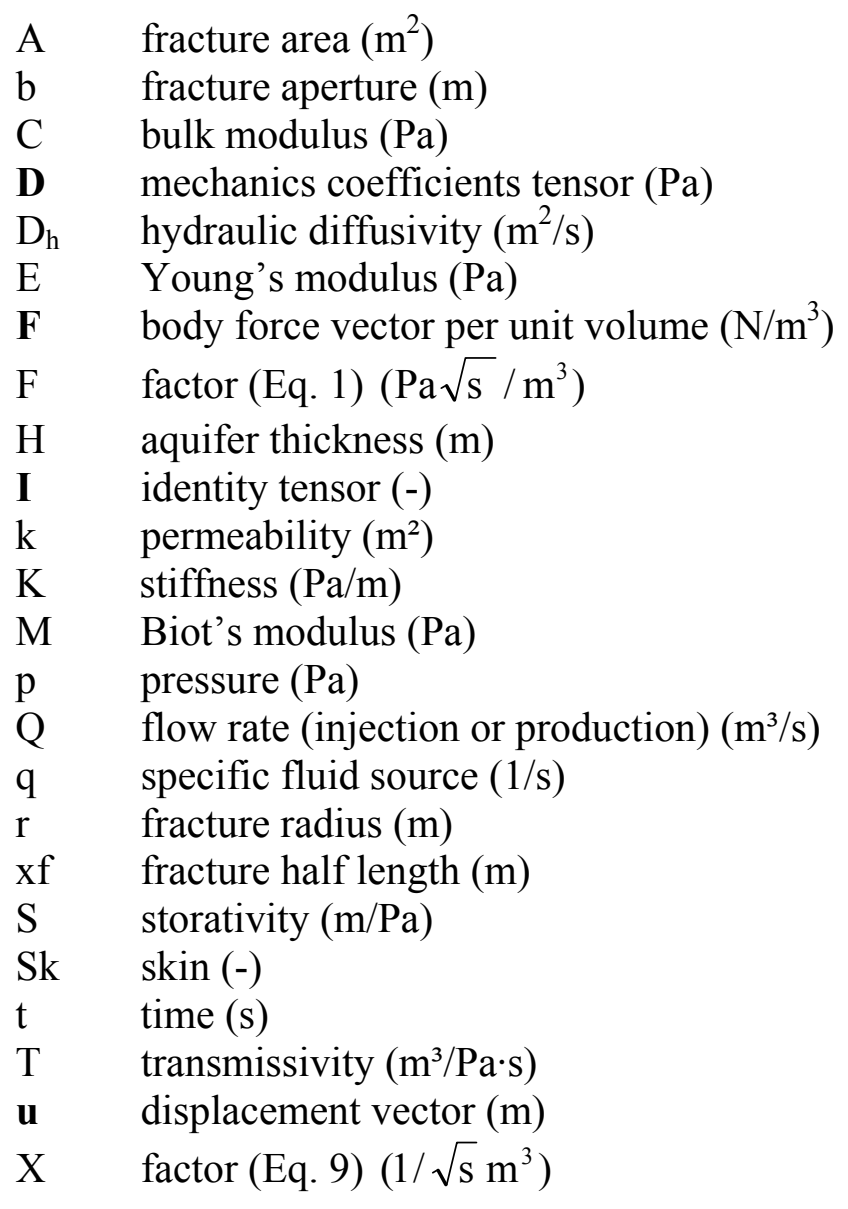

Greek symbols

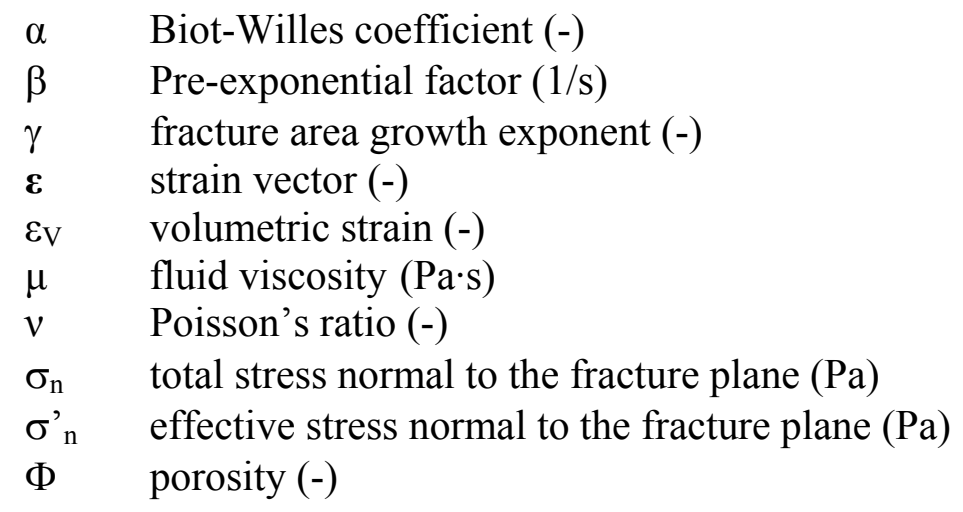

Subscripts 


$\begin{array}{ll}\mathrm{f} & \text { fracture } \\ \mathrm{fl} & \text { fluid } \\ \mathrm{g} & \text { grain } \\ \text { hist } & \text { history } \\ \mathrm{i} & \text { injection } \\ \mathrm{l} & \text { linear } \\ \mathrm{m} & \text { matrix } \\ \mathrm{n} & \text { normal } \\ 0 & \text { initial } \\ \mathrm{r} & \text { radial } \\ \mathrm{res} & \text { residual } \\ \mathrm{s} & \text { at shut-in start } \\ \mathrm{t} & \text { tangential }\end{array}$

Conversion: $1 \mathrm{~L} / \mathrm{s}=10^{-3} \mathrm{~m}^{3} / \mathrm{s}$

\section{Introduction}

Since the commercial viability of an Enhanced Geothermal System not only depends on high fluid production temperatures but also on high flow rates, reservoir stimulation is frequently used to increase well productivity (Murphy et al., 1999; Wallroth et al., 1999; Megél et al., 2006). In the case of hydraulic stimulation by massive fluid injection, coupled hydraulic and mechanical reservoir processes are involved. In particular, the coupled effect of mechanical fracture opening (causing rock deformation) resulting from increased fluid pressure in the fracture is important because fractures tend to be the main fluid flow pathways in tight (low-permeability) rock masses. Such hydromechanical effects were previously investigated numerically by Min et al. (2004), who determined the change in effective permeability of a fracture network for different loading conditions.

In recent years, some geothermal projects have been initiated to investigate the extraction of geothermal energy (i.e. heat) stored in tight sedimentary formations (see for example Orzol et al., 2004; Tischner et al., 2004; Legarth et al., 2005; MIT, 2006). After hydraulic stimulation, the systems hosted in sedimentary rocks are frequently described by simplified models that include a single (man-made) fracture.

Strongly coupled hydraulic and mechanical processes are described in the hydraulic fracturing context, in which the fluid pressure-induced opening of fractures increases the stress at the fracture tip until rock failure occurs and the fracture propagates; see Valko and Economides (1997) for a detailed overview. However, hydraulic fracturing theories and related approaches deal with the pressure regime where fractures propagate by tensile failure, which is above the minimum principal stress (also referred to as the closure pressure). Under this regime, the fluid pressure-induced fracture deformation depends on the mechanical properties (Young's modulus, Poisson ratio) of the bounding rock; hence, the fracture stiffness (a nonlinearly changing aperture below the closure pressure) is not considered. The change in fracture properties with respect to fluid pressure or loading variations has been investigated by a number of authors. For example, experiments have been performed to understand the interrelation between changes in fluid flow rates or fracture apertures and loading conditions (Olsson and Brown, 1993; Yeo et al., 1998; Sausse, 2002). Numerical investigations designed to understand the influence of normal and 
shear closure on fracture aperture were performed by Matsuki et al. (2006) and Ghassemi and Kumar (2007).

Whereas the investigations cited above aim to understand the hydromechanically controlled fracture opening and/or closure by way of laboratory experiments or numerical simulation, little efforts have been made to interpret hydraulic test data with respect to the fluid pressure-induced changes in fracture aperture. Thus, the influence of mechanically opening fractures on the fluid pressure response has rarely been described. Also, conventional pressure-transient analysis is restricted to relatively small volume, short-duration fluid injection operations followed by lengthy pressure falloff periods (Legarth et al., 2005; Craig, 2006). One possibility to investigate the fracture deformation with respect to fluid pressure changes is to perform pressure-step tests (jacking tests), as described in Singh et al. (1987), Rutqvist et al. (1992) and Lizak et al. (2006). In this case, the hydraulic aperture of fractures starts changing in a non-linear fashion while the injection pressure remains below the compressive stress across the fracture. Rutqvist (1995) presents the determination of fracture normal stiffness by a combination of in-situ pulse and jacking tests and numerical simulations, and defines a stress-permeability relation for fractures.

Here we analyze a huff-puff test (cyclic fluid injection/extraction) involving hydromechanically behaving fractures. By this behaviour we mean that the change in fluid pressure in the fractures affects the effective stress and thus causes mechanical fracture deformation (opening or closure), which in turn leads to a change in the hydraulic aperture and consequently influences fluid pressures. The test was performed in a geothermal sedimentary reservoir at $3800 \mathrm{~m}$ depth that had previously been stimulated by massive water injection. The analysis shows that only the consideration of such a hydromechanical fracture behaviour can explain the downhole pressure (build-up and decay) history that was recorded during the huffpuff test.

We will not deal with fracture propagation mechanisms because, for most parts of the test, the pressure is below fracture propagation level. Instead, we assume that fractures (artificially created by hydraulic stimulation) already exist in the reservoir at the time when the test began. Furthermore, we simplify our analysis by considering a model that only includes a single fracture. Of course, the more likely case that multiple fractures may actually exist is not addressed here, but the simplified model is adequate to explain the recorded downhole pressure changes. The analysis concentrates on the hydromechanical behaviour of the single fracture, which has been simulated with ROCMAS (Noorishad et al., 1992; Rutqvist et al., 1998); poroelastic effects in the bounding rock matrix are not investigated by the simulation.

In our study, we applied three different methods, which allow for varying degrees of complexity. The computer code 'Operation Data Analysis' (ODA) developed by Silin and Tsang (2002) was used to analyze the pressure behaviour in the traditional way, i.e. estimating hydraulic reservoir properties by curve fitting the measured pressure data against analytical solutions for radial and linear flow. The code is based on the conventional transient fluid flow model, but incorporates pre-test pressure distribution near the wellbore. An alternative analysis of hydromechanical effects was performed by curve fitting an analytical solution for the injection pressure that includes a time-dependent growth of fracture area (Silin and Patzek, 2001). This method can determine whether a changing fracture area would be an explanation for the observed pressure transients, but the resulting area proved to be unrealistically high. 
Instead, a change in the fracture volume (due to the fracture opening at injection) is a more reasonable explanation, as shown by a numerical simulation of fracture-matrix flow, whereby the fracture aperture becomes a function of the coupling between the rock deformation and the fluid pressure in the fracture. We use the finite-element code ROCMAS in our simulations. The analysis demonstrates that a combination of different approaches is useful and necessary to understand the processes involved throughout the entire hydraulic test. An analysis with only one approach, or an analysis of only parts of the test, may result in misinterpretations. In particular, the overall analysis has the advantage that the ambiguity of hydraulic test data interpretation can be reduced.

By comparing the huff-puff with the other hydraulic tests that were performed in the same reservoir, we will also demonstrate that the fracture must penetrate a layered medium with different rock permeabilities. Thus, the analysis we are presenting corroborates the fact that fractures show a complex hydromechanical behaviour in layered media, which depends on the hydraulic and mechanical properties of each layer and the property contrasts between layers (Warpinski and Teufel, 1987; Brenner and Gudmundsson, 2002; Gudmundsson et al., 2002).

Summarizing, the analysis presented herein determines from hydraulic tests the interplay between hydraulic and mechanical processes. Although the derived model still needs to be improved, such an analysis yields information about fracture (volume, length, storage capacity) and rock matrix (permeability or fluid leak-off behaviour) properties. In addition, the fracture stiffness, which describes the opening or closure of a fracture in response to pressure changes, can be estimated. Thus, injection/production flow rates can be adjusted to create an "open fracture" in which the fluid flow impedance becomes negligibly small. Open fractures allow the fluid to penetrate deep into the reservoir, resulting in a high heat exchange rate between the fluid and fracture walls. Therefore, it is also important to determine the behaviour of fractures in the different layers, which would help to identify the regions of the stimulated reservoir that are being affected by cold-water injection and by the production of hot fluids. In contrast, "closed fractures" (at low-pressure levels) will restrict the rate of heat extraction from the geothermal reservoir.

\section{The geothermal test site}

The hydraulic test under investigation was performed in well Horstberg Z1, which was drilled in 1987 some 40 km north-east of Celle, Lower Saxony, north-western Germany (Fig. 1). The original well was plugged back to $4120 \mathrm{~m}$ after it was declared as not being economical for gas production. Since 2003, the well has been reactivated for the pilot project GeneSys in order to evaluate different concepts for the exploitation of geothermal energy from tight sediments; see Orzol et al. (2004) for details.

If successful, the huff-puff technique would represent an innovation for geothermal energy production because it uses a single borehole, which considerably reduces investment costs. Evaluation of the proposed concepts was performed in the Middle Bunter (Lower Triassic) formation (3636-3926 m), which presents four sandstone horizons, i.e. Volpriehausen, Detfurth, Hardegsen and Solling (Fig. 2). The well is inclined $9^{\circ}$ from the vertical; its casing was initially perforated in the Volpriehausen and Detfurth horizons for the hydraulic test under investigation. Later, the Solling horizon was also connected to the wellbore by perforation. Fig. 2 also shows 
two temperature logs, which were acquired before (blue) and after (red) the stimulation of the Detfurth and Volpriehausen formations.

Between the sandstone units one finds claystones and sandstone-claystone alternating beds, which we presume as being homogeneous and isotropic for this study; see Röhling (1991) for a detailed description of the Middle Bunter. It is in fact likely that the studied layered formation is not isotropic, but a two-dimensional hydromechanical simulation (for which a layered formation cannot be considered) may be sufficient to understand the system. A more detailed analysis requires a three-dimensional model (see Section 5).

The main horizon under investigation is the Detfurth Sandstone (about $6 \mathrm{~m}$ thick), which is connected to the wellbore by casing perforations between 3787 and $3791 \mathrm{~m}$ depth. Hydraulic tests were performed in the Detfurth formation, three of which are presented briefly here. For downhole pressure measurements, a pressure gauge [Canada Tech Quartz (CTQ) II tool] was placed $13 \mathrm{~m}$ above the perforated zone. Hydraulic stimulation by massive $\left(20,000 \mathrm{~m}^{3}\right)$ fresh water injection into the Detfurth Sandstone was done in October and November 2003 (see Fig. 3 for pressure and flow rate recordings). After the last injection phase, the pressure decrease was recorded during an extended shut-in test lasting over five days. Although diagnostic measurements at the surface to characterize the fracture geometry and orientation failed (due to the great depth of the target horizon), the created fracture is believed to penetrate into the Solling Sandstone (Fig. 2). Later hydraulic communication tests (injection into the Detfurth and pressure recording in the Solling), which showed a time-delayed pressure response, and the temperature logs obtained before and after stimulation (see Fig. 2) confirm this conclusion.

In February 2004, a huff-puff test was performed through the Detfurth perforated zone (Fig. 4). The test included the injection of $2500 \mathrm{~m}^{3}$ of cold water over a 36 -hour period $(20 \mathrm{~L} / \mathrm{s}$ injection rate), which then heated up during the subsequent shut-in phase that lasted over 30 hours. This part of the test is termed the injection/shut-in phases. At the end of the injection phase, the downhole pressure $(68.5 \mathrm{MPa}$, Fig. 4) approached the fracture propagation pressure, which is indicated by the pressure plateau that was observed during the massive injection phases (Fig. 3).

After the injection/shut-in phases, five daily cycles of hot water production (15 hours) and shut-in (9 hours) were carried out (production/shut-in phases). Production of hot water was driven by the high pore pressure in the Detfurth formation that presents a naturally artesian reservoir with pressure approximately $23 \mathrm{MPa}$ above hydrostatic, yielding flow rates of about 9 L/s. In September 2007, a low-injection rate test, followed by a shut-in test, was performed in the Detfurth (Fig. 5). Compared to the other tests mentioned earlier, in this case injection took place over 45 hours with a small flow rate of approximately $2 \mathrm{~L} / \mathrm{s}$.

From these tests, hydraulic and mechanical reservoir properties could be determined (see table in Fig. 2 giving the parameters for the Detfurth Sandstone). The vertical stress prevailing in the Middle Bunter was estimated for a rock density in the $2500-2750 \mathrm{~kg} / \mathrm{m}^{3}$ range, since a density $\log$ was not available. Thee minimum horizontal stress was estimated by analyzing the shut-in pressure decline after the hydraulic stimulation; see Wessling et al. (2008) for more details. Nonoriented calliper logs (hence stress orientations cannot be determined) show that the Middle Bunter formation is very stable (i.e. no borehole breakouts were observed), so that further analysis of prevailing stresses could not be performed.

The permeability of the Detfurth Sandstone was estimated by pressure transient analysis (Tischner et al., 2004) and numerical simulation (Sulzbacher and Jung, 2004) of the 2004 huff- 
puff test (Fig. 4). A 3D simulation was performed assuming that the properties of an included fracture may differ between the three time intervals (see Fig. 4 for the intervals), but are constant during each of the intervals (fracture permeability: $0.6-1.5 \times 10^{-7} \mathrm{~m}^{2}$; fracture aperture: $0.85-$ $1.35 \times 10^{-3} \mathrm{~m}$ ). Thus, the hydromechanical opening and closing caused by pressure changes in the fracture was not considered in this model.

The division into three intervals should compensate for aperture variations in hydromechanically responding fractures caused by fluid pressure changes, so that the simulation results fit the measurements at least for the five production cycles. However, the measured pressure build-ups during injection and pressure declines during the first shut-in phase differ appreciably from those of the simulation that assumes a fracture with constant hydraulic properties (Fig. 4). Therefore, an aspect of the test that needs to be clarified is the pressure buildup and decline for the injection and shut-in phases, respectively.

Obviously, the pressure decline after high- and low-flow rate injection is different. For both tests that used high injection rates (Figs. 3 and 4), the pressure fall-off is very slow. Even after five days, the pressure does not get back to the reservoir pressure measured after the hydraulic stimulation (Fig. 3). The same behaviour (a nearly linear pressure decline) is observed at the first shut-in phase of the huff-puff test (Fig. 4). In contrast, the pressure fall-off after the low-rate injection test (Fig. 5) is symmetric to the pressure build-up at injection, as one would expect from a conventional hydraulic test interpretation without hydromechanically responding fractures (for example, see Chapter 4 in Bourdarot, 1998).

Here we will focus on the analysis of the pressure behaviour at injection and subsequent shut-in during the February 2004 huff-puff test (Fig. 4), and compare the analysis results to the pressure measured during the post-stimulation shut-in phase and the low-injection rate test.

\section{Analysis of huff-puff test data}

This section presents three approaches to analyse the downhole pressures recorded during the huff-puff test and to develop the physical model shown in Fig. 6. Hydraulic stimulation in the Detfurth formation created a vertical fracture (x-z plane), which propagated into overand underlying formations of lower permeability. At the beginning of the huff-puff test (injection), the upper and lower boundaries of that fracture are sufficiently close so that flow takes place in the Detfurth Sandstone only. Consequently, the preferential flow pattern is linear. Continuous injection opens the fracture in the transverse y-direction as a mechanical response of the formation to the fluid pressure build-up in the fracture. In addition to the change into a radial flow pattern, the fracture storage capacity increases substantially. At shut-in, very slow pressure fall-off takes place because the fluid stored in the fracture leaks into the low-permeability formations, whereupon the fracture starts closing. The following production phase causes the fracture to close still further. Somewhere during this phase, the large fracture becomes less important, and the flow regime changes back from radial to linear, mostly in the stimulated Detfurth formation.

Two of the three analysis methods used hereunder have limited capability to consider the influence of hydromechanical processes on the pressure recordings. It is nevertheless worth presenting analysis results that indicate the occurrence of hydromechanical fracture opening/closure during fluid injection/production; therefore the results obtained with these two 
approaches are described briefly. A more extended description is given for the numerical simulation using ROCMAS (see Section 3.3).

\subsection{ODA-fits}

The ODA code is particularly applicable for fitting pressure curves irrespective of previous activities, because it considers an additional parameter, $Q_{\text {hist, }}$, that depends on previous fluid injection (or production) history (Silin and Tsang, 2002). If the actual flow rate history is available, the estimated value of $Q_{\text {hist }}$ is used to evaluate the quality of data fitting.

Fitting pressures with the ODA code can be performed by choosing either a radial or a linear flow model. The input data are flow rates and downhole pressure time series. The following procedure is used. First, one selects a time interval for analysis; let $t_{0}$ and $t_{2}$ be its start and end times. The fitting is performed on an interval between $t_{1}$ and $t_{2}$, where $t_{1}$ is some time between $t_{0}$ and $t_{2}$. The fitting parameters are transmissivity, storativity, skin factor, and $Q_{\text {hist. }}$ For linear flow, the increase in the downhole pressure is proportional to parameter $\mathrm{F}$,

$$
F=\frac{\mu \sqrt{D_{h}}}{2 \sqrt{\pi} k_{m} A}
$$

which is the factor in front of the integral in Eq. 26 of Silin and Patzek (2001). Here, $\mu$ is fluid viscosity, $\mathrm{k}_{\mathrm{m}}$ is matrix permeability, $\mathrm{Dh}_{\mathrm{h}}=\mathrm{T} / \mathrm{S}$ is hydraulic diffusivity ( $\mathrm{S}$ is storativity and $\mathrm{T}$ is the transmissivity), and $\mathrm{A}$ is the fracture area, which is assumed to remain constant in ODA. If a radial flow model is specified, ODA gives, instead of $\mathrm{F}$, the storativity $\mathrm{S}$ and transmissivity $\mathrm{T}$, which is defined as

$$
T=\frac{k_{m}}{\mu} H
$$

where $\mathrm{H}$ is the aquifer thickness. For our proposed model, the application of the cubic law for fracture transmissivity $\left(T_{f}=b^{3} / 12 \mu\right.$; see Witherspoon et al., 1979, 1980) is reasonable, because the determination of $b$ (fracture aperture) from the estimated ODA fit is found to be comparable to the simulation results with ROCMAS (see Section 4).

Analyzing the entire huff-puff test data set with ODA, we found that the curve fitting with either flow model (i.e. linear or radial) is rather poor. In particular, the fit to the injection and the first shut-in phase deviates from the pressure recordings (Fig. 7). This observation implies that the processes taking place during the huff-puff test cannot be described by a set of constant parameters as specified in Eqs. (1) and (2) when using ODA.

ODA fits were found to be more accurate if only parts of the huff-puff test were analyzed. For example, a fit with a linear flow model could be performed for the first two hours of the injection phase. After that, the subsequent part of the injection phase (2-36 hours) could be fitted with a radial flow model (Fig. 7). Parameters obtained from the ODA fits are given in Table 1. Although the estimated history sources, $Q_{\text {hist}}$, do not exactly match the real injection rates, their values are of reasonable magnitude. According to the conventional notation, the positive skin factor denotes a flow restriction in the borehole vicinity. 
A transition from linear to radial flow is usually observed in the later stages of an injection test, when the radially distributing pressure front in the rock matrix exceeds the fracture length (see Fig. 8). For this test, the observation of an early change (after 2 hours) from linear to radial flow would thus imply that the fracture length is rather small.

We propose a different scenario (and will prove its validity) supported by the good fit with a radial flow model (Fig. 7). We believe that at the beginning of injection the pressure response at the wellbore is controlled by linear flow in a partially open vertical fracture confined to the rather thin Detfurth Sandstone (Fig. 6; left panel). That fracture is permanently open even at the ambient reservoir pressure. This observation is confirmed by the pressure transients analysis of Tischner et al., 2004, who showed that formation linear flow due to an existing fracture prevails at pressure magnitudes around pore pressure $(60 \mathrm{MPa})$. Continuous pressure increase causes the hydromechanical opening of a large fracture in the vertical direction, so that the water injected through the 4-m long perforation zone now starts spreading radially (Fig. 6; right panel).

The semi-log plot shown in Fig. 9 gives a further evidence of the occurrence of radial flow at high pressure. The straight line after two hours of injection proves that the pressure increase behaves according to the logarithmic law, which indicates radial flow (Bourdarot, 1998).

Again, the ODA analysis of the entire production/shut-in interval (95-215 hours) results in a rather poor fit (Fig. 7). Due to this drawback, each production/shut-in pair was analyzed separately, from which the following observations were made (see Fig. 10): (1) both flow models yield a reasonably good fit for the interval $t_{1}-t_{2}$, and (2) For the interval $t_{0}-t_{1}$ a better fit could be obtained with the radial model. Most important is the observation that the extrapolation at times $t$ $>t_{2}$ follows a decreasing pressure trend when a linear flow model is assumed. This trend results from the fact that each production phase starts before the pressure has declined to the ambient reservoir pressure of $60 \mathrm{MPa}$. Hence, for the linear model a continuous pressure drawdown takes place throughout the complete production/shut-in regime. If a radial flow model is assumed, this overall pressure drawdown is not observed. Instead, the pressure level remains more or less constant at extrapolation. We conclude from these observations that a linear flow model is more likely to be appropriate to describe the flow regime during production/shut-in at a low-pressure level (as was also concluded by Tischner et al., 2004).

\subsection{Analytical solution for fracture growth area}

A further analysis of the data can be done by calculating the injection pressure under the assumption of a growing fracture area. Assuming a constant injection rate $Q$, a small fracture volume and a high fracture permeability, compared to that of the rock formation, equation (28) in Silin and Patzek (2001) implies:

$$
p_{i}(t)=p_{0}+\frac{\mu}{\sqrt{\pi}} \frac{\sqrt{D_{h}}}{k_{m} A(t)} \sqrt{t} Q
$$

where $\mathrm{p}_{0}$ is the initial pressure. Note that the term 'fracture growth area' does not mean fracture propagation, but an increase in the fracture area over which the fracture can be assumed to be highly conductive compared to the formation. In that part of the fracture, the flow regime is controlled by a predominant pressure gradient in the formation and is perpendicular to the fracture (see Fig. 8; left panel). The resulting linear flow regime in the formation exhibits a 
square root of time dependency of pressure in Eq. (3), and is controlled only by the formation parameters (hydraulic diffusivity $\mathrm{D}_{\mathrm{h}}$ and matrix permeability $\mathrm{k}_{\mathrm{m}}$ ) and the growing fracture area. Fracture parameters do not affect this flow regime.

A fracture growth rate versus time expression was derived by Gordeyev and Zazovsky (1992), who showed that for a fracture of constant height (i.e., the fracture does not grow in the vertical direction), a linear fracture propagation obeys the equation:

$$
A(t)=A_{0}\left[1+\beta\left(t / t_{0}\right)\right]^{1 / 4}
$$

A similar power-law approximation to surface growth is given by Nolte (1979), who for a constant injection rate assumed that the fracture area evolves according to:

$$
\frac{A}{A_{s}}=\left(\frac{t}{t_{s}}\right)^{\gamma}
$$

where $A_{s}$ is the fracture area at the end of injection at time $t_{s}$, and $\gamma$ is the fracture growth exponent (for a detailed description see also Valko and Economides, 1997).

Thus, there is reasonable theoretical basis to assume fracture growth versus time obeys a power-law relationship, which is for this study

$$
A(t)=A_{0}\left(1+\beta \Delta t^{\gamma}\right)
$$

Here, $\Delta t=t-t_{0}$ is the time difference between the initiation of fracture growth at $t_{0}$ and time $t$. The initial fracture area is assumed to be:

$$
A\left(t=t_{0}\right)=A_{0}
$$

With the assumption of constant viscosity ${ }^{1}$, the first fraction $\mu / \sqrt{\pi}$ in Eq. (3) is constant, whereas the second fraction $\sqrt{D_{h}} / k_{m} A(t)$ has to be fitted to the measurements. For this study, an analysis of fracture growth was performed for the injection phase, up to the beginning of the shut-in at the time $t_{s}$. The period being analyzed begins at some time $t_{0}$ after the start of injection to account for the fact that the analytical solution (i.e. Eq. 3) is only valid for growing fractures of high transmissivity. Hence, at the beginning of injection, the fracture needs to open first.

For time $\mathrm{t}<\mathrm{t}_{\mathrm{s}}$ the analytical solution is formulated as

$$
p_{i}(t)=p_{0}+\frac{\mu}{\sqrt{\pi}} X_{i}\left(\Delta t_{i}\right) \sqrt{t} Q
$$

where

1 This is a major assumption that may not hold for large temperature differences within the fluid. However, we believe that the observed pressure is mainly affected by the high hydraulic conductivity of the fracture and its mechanical opening, whereas the fluid temperature in the fracture rapidly equilibrates with the formation temperature. 


$$
X_{i}\left(\Delta t_{i}\right)=\frac{\sqrt{D_{h}}}{k_{m} A_{0}\left(1+\beta_{i}\left(\Delta t_{i}\right)^{\gamma_{i}}\right)}
$$

and $\Delta \mathrm{t}_{\mathrm{i}}=\mathrm{t}_{\mathrm{t}} \mathrm{t}_{\mathrm{f}}$ for $\mathrm{t}<\mathrm{t}_{\mathrm{s}}$. For the formulation of $\mathrm{X}_{\mathrm{i}}\left(\Delta \mathrm{t}_{\mathrm{i}}\right)$, we assume constant, yet unknown, values for the hydraulic diffusivity $D_{h}=k_{m} / \mu S$ and the matrix permeability $k_{m}$. At initial fracture growth time,

$$
X_{0}\left(t_{0}\right)=\frac{\sqrt{D_{h}}}{k_{m} A_{0}} .
$$

The fitting was performed by minimizing the relative error $\delta_{\mathrm{r}}$ between the measured and calculated pressures. For the injection phase, the pressure was calculated according to Eq. (8), with the fitting parameters $\mathrm{A}_{0}, \beta_{\mathrm{i}}$, and $\gamma_{\mathrm{i}}$ (Eq. 9). For the values given in Table 2, the results for the best fits are presented in Fig. 11. In addition, the figure shows two trials for lower initial values of $X_{0}$. The time-dependent fracture area was calculated from Eq. (9), assuming constant fluid viscosity and storativity per unit thickness $\left(\mu=3 \times 10^{-4} \mathrm{~Pa} \cdot \mathrm{s}\right.$ and $\left.\mathrm{S} / \mathrm{H}=2 \times 10^{-11} \mathrm{~Pa}^{-1}\right)$.

The injection pressure can be fitted by the analytical solution, assuming a power-law dependency of the fracture growth versus time. The solution suggests that, after a short time of injection, a rather large fracture exists, whose highly conductive part grows with continued injection. However, the fracture area is rather large for tight sedimentary reservoirs of moderate permeability. For a matrix permeability of $k_{m}=10^{-18} \mathrm{~m}^{2}$, the fracture area at the end of the injection period is $A_{s}=2 \times 10^{6} \mathrm{~m}^{2}$, which was calculated using the following equation,

$$
A_{s}=\frac{\sqrt{D_{h}}}{k_{m} X_{s}\left(t_{s}\right)} .
$$

In evaluating Eq. (11), $\mathrm{X}_{\mathrm{s}}$ from Table 1 was used. One possible explanation for this extremely large fracture area is the fact that the analytical solution does not consider an increase in the fracture volume, which is an important aspect of the hydromechanical opening of large-area fractures.

\subsection{Simulation with ROCMAS}

So far, the highly asymmetric pressure behaviour during the shut-in phase (Fig. 4) could not be explained. Therefore, we used the numerical simulator ROCMAS (acronym for ROCk Mass Analysis Scheme), which is a finite element computer program for coupled flow and stress analysis of deformable, saturated, fractured rock media (Noorishad et al., 1992; Rutqvist et al., 2001). This code treats coupled hydromechanical behaviour by a combination of isothermal transient pressure and stress-strain analyses in formations with discrete fractures and porous blocks. Thermal flow is supported by ROCMAS, but would complicate the interpretation of simulation results. Of course, an extension of the simulation model includes stress changes due to thermal expansion coupled to thermal energy transport by the fluid (convection) and the solid

matrix (conduction), but such processes are likely to be of lesser importance compared to stress 
changes that are a consequence of massive water injection over a short period of time (compared to the expected commercial lifetime of a geothermal reservoir). Coupling of the fluid flow and mechanical deformation is based on an extension of Biot's consolidation theory (Biot, 1941) that considers the response of a porous elastic medium to non-linear fracture behaviour.

In the ROCMAS simulator, hydromechanical processes for the rock matrix are formulated as (Rutqvist and Stephansson, 2003),

$$
\begin{aligned}
& \nabla \bullet\left(\mathbf{D} \frac{\partial \boldsymbol{\varepsilon}}{\partial t}\right)-\nabla \bullet\left(\alpha_{m} \mathbf{I} \frac{\partial p}{\partial t}\right)=\frac{\partial \mathbf{F}_{m}}{\partial t} \\
& \nabla \bullet\left(\frac{k_{m}}{\mu} \nabla p\right)-\alpha_{m} \frac{\partial \varepsilon_{V}}{\partial t}-\frac{1}{M_{m}} \frac{\partial p}{\partial t}=q
\end{aligned}
$$

where $\mathbf{D}$ is a tensor of elastic constants containing Young's modulus E and Poisson's ratio $v$. $\mathbf{I}$ is the identity tensor, $\alpha_{m}$ is the Biot-Willis coefficient (Biot and Willis, 1957), and $\varepsilon$ is a column vector containing normal and shear strains. Also note that $\nabla \bullet \mathrm{A}$ is the divergence of a vector A. In Eq. (13), $k_{m}$ is the matrix permeability (assuming isotropy) and $M_{m}$ is Biot's modulus, which is defined as (Rutqvist and Stephansson, 2003),

$$
\frac{1}{M_{m}}=\Phi / C_{f l}+\left(\alpha_{m}-\Phi\right) / C_{g}
$$

where $\Phi$ is porosity, $C_{\mathrm{fl}}$ and $\mathrm{C}_{\mathrm{g}}$ are the bulk moduli of fluid and solid grains, and $q=Q / V$ is the specific fluid source term including gravity effects. $\mathbf{F}_{\mathrm{m}}$ is the body force vector per unit volume (see also Jaeger et al., 2007).

For the fracture, stress balance and fluid flow equations are formulated as,

$$
\begin{aligned}
& \nabla \bullet\left(\mathbf{K} \frac{\partial \mathbf{u}}{\partial t}-\alpha_{f} \frac{\partial p}{\partial t}\right)=\frac{\partial \mathbf{F}_{f}}{\partial t} \\
& \nabla \bullet\left(\frac{k_{f}}{\mu} \nabla(p+\rho g z)\right)-\frac{\alpha_{f}}{b} \frac{\partial u_{n}}{\partial t}-\frac{1}{M_{f}} \frac{\partial p}{\partial t}=q
\end{aligned}
$$

where the fracture permeability is defined as

$$
k_{f}=\frac{b^{2}}{12}
$$

and the volumetric strain (assuming equality between mechanical and hydraulic aperture) is approximated as

$$
\frac{\partial \varepsilon_{V}}{\partial t} \approx \frac{1}{b} \frac{\partial u_{n}}{\partial t}
$$


In Eq. (17), $\mathbf{u}$ is the displacement vector with the components normal displacement, $u_{n}$, and tangential displacement, $u_{t}$, and the vector

$$
\mathbf{K}=\left(\begin{array}{l}
K_{n} \\
K_{t}
\end{array}\right)
$$

describes the normal and tangential stiffness of the fracture. Stiffness relates normal and shear (in tangential fracture direction) deformation of the fracture due to changes in effective normal or shear stress (Goodman, 1974). For example,

$$
\Delta u_{n}=\Delta \sigma_{n}^{\prime} / K_{n}
$$

where $\sigma_{n}^{\prime}=\sigma_{n}-\alpha p$ is the effective normal stress $\left(\sigma_{n}\right.$ is the total stress normal to the fracture plane). Here, the fracture aperture is given by:

$$
\sigma_{n}^{\prime}=\sigma_{n}-\alpha p=\frac{\sigma_{n 0}^{\prime} b_{0}}{b}
$$

where $b_{0}$ is the reference (initial) fracture aperture at the initial effective normal stress $\sigma^{\prime}{ }_{n 0}$.

Due to the ODA observation of radial flow after a short injection period (see Section 3.1), we used a radial flow model for 2D ROCMAS simulations. We assumed the following setup (see Fig. 12). Assume the vertical fracture to be circular, with its center in the perforation location ( $x$ $=0, y=0$ ). Consider this fracture as being part of the top of a larger radius cylinder, whose axis points in the y-direction. Now, cut the cylinder into its radians and discretize the one in the $x-y$ plane for the simulation. The fractures in this discretization plane are thus 1D structures that are located along the $\mathrm{x}$ axis.

Thus, in case of radial flow, ROCMAS solves the governing equations for a r-y cylindrical coordinate system assuming the primary variables (pressure, displacements) being independent of the angle coordinate, but the thickness of a finite element is a function of the radius divided by $2 \pi$. If linear flow is simulated, the discretization plane just represents a $2 \mathrm{D}$ horizontal structure (x-y plane) of unit thickness within the Detfurth Sandstone. The assumption of radial fracture geometry is a simplification because, in reality, the fracture shape depends on the stress gradient, and is therefore more likely to be elliptical.

The setup also includes an additional fracture (Fracture 2 in Fig. 12) beyond the hydromechanically responding one (Fracture 1). Fracture 2 was included to avoid numerical instabilities at the fracture tip, but it leads to interesting effects during injection. The aperture of the Fracture 2 was set one order of magnitude smaller than that of Fracture 1, so that its contribution to fluid flow remains small. Also, a residual fracture aperture $b_{\text {res }}$ was introduced which, however, is not reached in Fracture 1 during the simulation. For simplicity, in this model the closure pressure is set to $\sigma_{\mathrm{n}}=68.5 \mathrm{MPa}$, hence the effective normal stress becomes zero at that pressure. 
Fracture apertures computed using Eq. (21), $\sigma_{\mathrm{n}}=68.5 \mathrm{MPa}$ and the parameters given in Table 3 are presented in Fig. 13. In addition, the figure shows results for the mechanically responding fracture aperture model (according to Eq. 20) that was used in the linear flow model simulation. The curve for the linear flow model indicates that hydromechanical effects are small (due to the high normal stiffness $\mathrm{K}_{\mathrm{n}}$; see Table 3) compared to the Goodman (1974) model for radial flow.

The Goodman model used here does not distinguish between fracture opening above and below the closure pressure. Hence, different mechanical responses are not included, i.e. below fracture closure (controlled by stiffness) and above fracture closure (controlled by rock elasticity). However, the model is appropriate for simulating hydromechanical fracture opening and closing.

For the simulation, matrix permeability $\left(\mathrm{k}_{\mathrm{m}}\right)$ and fracture radius $(\mathrm{r})$ were the main fitting parameters. Typical values of Poisson's ratio and Young's modulus for sediments were chosen (see for example Kulhawy, 1975). The rock porosity of $5 \%$ is a typical value for the dense sandstones in the reservoir under consideration. Biot's constant $\alpha_{m}=1$ corresponds to full hydromechanical coupling between flow and rock mechanics, i.e. equivalent to a Terzaghi effective stress law. The Biot's modulus $\mathrm{M}_{\mathrm{m}}$ can be estimated according to Eq. (14). For $\alpha_{\mathrm{m}}=1$, the bulk modulus $\mathrm{C}_{\mathrm{g}}$ is very high (Nur and Byerlee, 1971; Garg and Nur, 1973; Rutqvist and Stephansson, 2003), so that $\mathrm{M}_{\mathrm{m}}=\mathrm{C}_{\mathrm{fl}} / \Phi$. Thus, for $\mathrm{C}_{\mathrm{fl}}=2.3 \mathrm{GPa}$ as the bulk modulus of water, $\mathrm{M}_{\mathrm{m}}=44 \mathrm{GPa}$ for the matrix $(\Phi=0.05)$ and $\mathrm{M}_{\mathrm{f}}=2.3 \mathrm{GPa}$ for the fracture $(\Phi=1)$.

No fluid flow conditions were assigned to the lower $(\mathrm{y}=0 \mathrm{~m})$ and left $(\mathrm{r}=0 \mathrm{~m}$ or $\mathrm{x}=0 \mathrm{~m}$ for radial or linear setup) boundaries (ensuring symmetry), and a constant pressure of $\mathrm{p}=60 \mathrm{MPa}$ was set at the upper $(\mathrm{y}=5000 \mathrm{~m})$ and right $(\mathrm{r}, \mathrm{x}=5000 \mathrm{~m})$ boundary. In addition, the upper and lower boundaries were fixed in the y-direction, and the left and right ones in the $\mathrm{x}$-direction (nodisplacement mechanical boundary conditions). An injection source of $Q_{r}=0.02 /(2 \times 2 \pi) \mathrm{m}^{3} / \mathrm{s}$ is placed at the lower left corner of the model (division by 2 is due to symmetry in the y direction; division by $2 \pi$ is because only one radian of the system is simulated).

For the parameters given in Table 3, the calculated pressures at the injection point are given in Fig. 14. In addition, the figure presents simulation results obtained from the assumption of a linear flow model (parameters are also given in Table 3). For the linear flow case, a 6-m thick Detfurth was assumed, so that the injection source becomes $Q_{1}=0.02 /(4 \times 6) \mathrm{m}^{3} / \mathrm{s}=8.3 \times 10^{-3}$ $\mathrm{m}^{3} / \mathrm{s}$. Division by four is due to the symmetry assumption (only one quarter of the system was simulated), and division by six is because the fluid is injected into a 6-m thick layer.

For the linear and the radial flow model a reasonable fit is obtained for the injection phase (Fig. 14). However, simulation with a radial flow model underestimates the pressure behaviour at the beginning of injection, with the simulated pressure increase being less steep. This is because the radial flow model is not appropriate here, as was already suggested by the ODA fit.

More important is a consideration of the shut-in phase, where the asymmetric pressure decline was observed. The linear flow model fails for this phase; the modelled pressure decline is rather symmetric to the pressure increase at injection, as one would expect from pressure buildup/fall-off curves in conventional hydraulic systems (where the superposition principle applies). The simulations with the radial flow model show a good agreement; in particular, the simulation reflects the nearly linear pressure fall-off. Also, an extended calculation of the pressure fall-off 
during shut-in shows the same trend as observed in the elongated shut-in phase after the second massive water stimulation (Fig. 3).

A further interesting observation is the opening of the Fracture 2 during injection. As Fig. 15 shows, there is an increase in aperture at the intersection between Fractures 1 and 2 due to the opening of the latter. Also, the length over which the pressure is uniform increases towards the end of the injection phase (Fig. 16; upper panel). This observation may be attributable to an increasing fracture area, as was already determined by the analytical solution. Note that 'increasing fracture area' does not mean fracture propagation, but an increase in the area over which the fracture is highly conductive (due to its larger aperture) compared to the rock matrix. A similar phenomenon may be observed if a large fracture penetrates layered media. However, more important than this 'fracture growth' is the fact that, according to the simulations, the fracture volume increases substantially due to the fracture opening. The fracture storativity as calculated from the ROCMAS simulation output becomes for the injection phase $S_{f}=\partial b / \partial p=10^{-3} \mathrm{~m} / \mathrm{MPa}$ (use pressure and aperture differences between $\mathrm{t}=31$ and 36.5 hours, Figs. 15 and 16). This storativity states that a pressure increase of one MPa widens the fracture by $1 \mathrm{~mm}$, which is a reasonable specific fracture storativity value (Rutqvist et al., 1998).

Finally, the simulations were continued for the production/shut-in phases, during which the measured pressure also showed a steeply decreasing trend. It is interesting to recognize that during production, within the first phase after shut-in, the simulation results fit reasonably well. The continuous simulation with ROCMAS shows an adequate and physically reasonable pressure response to the flow rates. However, the modelled pressure at the beginning of production presents the same underestimation of pressure behaviour as at the beginning of injection. In addition, the pressure trend at shut-in shows a linear slope similar to that simulated and observed at the first shut-in phase (after injection).

In conclusion, the simulation with ROCMAS is appropriate to reproduce the hydromechanical fracture behaviour during the injection/shut-in phases. Continuing with the same radial model, however, results in a pressure behaviour that differs from the observations. Thus, during the production/shut-in phases the ROCMAS simulation (radial model) is less precise than the 3D hydraulic-only modelling done by Sulzbacher and Jung (2004). This indicates that the radial flow model is not appropriate for the production/shut-in phases.

To analyze further the pressure decline at shut-in we studied the change in fracture aperture during this phase. Fig. 15 shows that, with increasing time, the aperture remains rather uniform over the entire fracture radius; hence the storage capacity of the fracture increases with the injected fluid volume. Even more important is the fact that the same aperture behaviour is observed during shut-in, i.e., the fracture closes over the entire fracture radius (Fig. 15; lower panel) due to fluid leakage into the rock formation. Thus, in this phase, the fracture area does not shrink significantly. Rather, the storage of the fracture is decreasing. Of course, such an effect can only be explained by considering hydromechanical effects in the fracture-matrix system.

The aperture increase over the entire fracture radius is explained by the pressure distribution in the fracture (Fig. 16). The upper panel of the figure shows that the pressure becomes more or less uniform after a short injection time. At shut-in, the pressure decreases uniformly over the entire fracture radius (Fig. 16; lower panel). The aperture versus pressure behaviour changes during the production/shut-in phases. For times greater than $78 \mathrm{~h}$, the fracture aperture remains 
more or less constant (Fig. 15, lower panel), but the pressure decreases in the near field (i.e. close to the borehole) and remains uniform at greater radii (Fig. 16, lower panel). This pressure decrease in the near field is probably the reason why the simulated pressure behaviour at the beginning of the production and shut-in phases (Fig. 14) is much steeper than observed.

To further analyze near-field effects we studied the fracture aperture and fluid pressure histories at $\mathrm{x}=40 \mathrm{~m}$. The pressure does not show a large decrease or increase at the beginning of the production and shut-in periods (Fig. 17). In addition, a change in aperture is observed throughout the test, which indicates hydromechanical effects persisting during the injection/shutin phases. Meanwhile, the pressure decline at shut-in shows an essentially linear slope.

Furthermore, it is interesting to note that the interplay between the sudden opening of Fracture 2 (Fig. 15), which is indicated by its increase in aperture, and the resulting change in the opening behaviour at $\mathrm{x}=40 \mathrm{~m}$ (at about 30 hours; Fig. 17) is not visible in the pressure behaviour (Fig. 16; upper panel) at the wellbore. Here, the pressure still increases continuously without any sudden changes in slope.

\section{Discussion and conclusions}

Our study shows that none of the applied techniques is able to explain the entire huff-puff test data set. ODA fits are restricted to specific parts of the test, but show that different flow regimes (linear or radial) prevail during the various phases of the experiment, which indicates the occurrence of hydromechanical processes in the fracture. The analytical solution considering fracture growth and shrinkage shows a good fit for the injection phase, but the fracture behaviour at shut-in cannot be explained.

For the shut-in phase, the ROCMAS simulation gives more insight into fracture behaviour. However, the two-dimensional setup that was used does not allow a consideration of changes in the flow regime, so that the production/shut-in phases are poorly fitted. The results also show that an analysis of only parts of the test can lead to misinterpretations. For example, the injection phase proved to be reproducible by the hydromechanical ROCMAS simulation with either linear or radial flow models (considering different rock permeabilities). However, a consideration of the results obtained with different approaches is a promising way to investigate the hydromechanical behaviour of the assumed fracture during the entire hydraulic test. The combined analysis of the injection and shut-in phases constrains the number of possible solutions considerably.

According to the ROCMAS simulations, the pressure increase during injection is mainly explained by the growth in storage volume due to fracture opening. The increase of the fracture radius as indicated by the opening of Fracture 2 (see Figs. 15 and 16) is small compared to the fracture growth given by the analytical solution (Eq. 3). One should remember that this solution does not consider an increase in fracture volume, hence changes in the storage capacity of an opening fracture are not included in the analysis. This is probably the reason why the calculated fracture area based on the analytical solution is unrealistically high.

The fracture in the ROCMAS setup is assumed to be radial, which is consistent with the ODA observations. This geometry provides a large fracture volume, which increases during injection. At the end of injection, the volume of the fracture is about $\mathrm{V}_{\mathrm{f}}=\pi \times(250 \mathrm{~m})^{2} \times\left(3 \times 10^{-3}\right.$ $\mathrm{m}) \approx 589 \mathrm{~m}^{3}$ (i.e., the fracture radius is $250 \mathrm{~m}$, and $3 \times 10^{-3}$ is the fracture aperture given in Fig. 15). Thus, the fracture has a huge storage capacity for the injected water. 
The simulations prove that the hydromechanical widening (at injection) and closing (at shutin) of a large fracture embedded in a low-permeability formation is the reason for a very slow pressure decrease at shut-in. In other words, the pressure behaviour is mainly affected by a hydromechanical change in fracture fluid storage. This effect is also observed during the poststimulation shut-in phase (Fig. 3), where the pressure fall-off is very slow. It should nevertheless be mentioned that leakage into the more or less impermeable formation still takes place. The ratio of total fluid volume injected $\left(2600 \mathrm{~m}^{3}\right)$ to the fracture volume at the end of injection $\left(589 \mathrm{~m}^{3}\right)$ shows that, during injection, about $77 \%$ of the fluid leaked into the surrounding formation.

Assuming linear fracture geometry, (i.e. a fracture confined only to the Detfurth Sandstone) one might expect similar pressure behaviour at shut-in, as long as the fracture volume and the hydraulic properties (e.g. $\mathrm{k}_{\mathrm{m}}=10^{-18} \mathrm{~m}^{2}$ ) are comparable to the radial fracture geometry case. Thus, assume a 6-m thick Detfurth, which is (a) a plausible value obtained from logging information, and (b) sufficiently small to ensure more or less linear flow of the water entering the fracture through a 4-m high perforation. Then, to obtain the same fracture volume as for the radial geometry case $\left(590 \mathrm{~m}^{3}, 3-\mathrm{mm}\right.$ aperture $)$, the fracture length would have to be $33 \mathrm{~km}$, which is clearly unrealistic. Likewise, one might argue that a similar fracture volume could be achieved by considerably increasing the fracture aperture, but it is unlikely that the aperture would exceed a few millimetres as a result of the injection of a low-viscosity fluid like water.

The production/shut-in phases do not show strong hydromechanical effects, as can be seen from the nearly constant apertures along the fracture given by the ROCMAS code (Fig. 15). Also, the purely hydraulic simulations performed previously gave a good fit for these phases, even without changing the fracture aperture (see Sulzbacher and Jung, 2004). According to the modelling results, the reason why the results of the purely hydraulic simulations give a better fit than those of the hydromechanical model is that the flow regime changes with the pressure levels. At low pressure, linear flow takes place in the more permeable Detfurth Sandstone, which is also confirmed by the pressure fall-off observed after the low-injection test (Fig. 5).

A further analysis proves consistency between the conclusions from the ODA fit and the ROCMAS simulation. Assuming radial flow in the large fracture, the parameter $\mathrm{H}$ in Eq. (2) is not the aquifer thickness but the fracture aperture $b$. Thus, assuming the validity of the cubic law (Witherspoon et al., 1979, 1980), the transmissivity obtained from the ODA fit can be expressed in terms of a fracture transmissivity,

$$
T_{f}=\frac{b^{3}}{12 \mu}
$$

which gives the width of the fracture. Hence, one should be able to calculate the fracture aperture from the transmissivity given by ODA. For $\mathrm{T}_{\mathrm{f}}=4.42 \times 10^{-10} \mathrm{~m}^{3} /(\mathrm{Pa} \cdot \mathrm{s})$ (Table $1, \mu=3 \times 10^{-4}$ $\mathrm{Pa} \cdot \mathrm{s})$, the fracture aperture becomes $\mathrm{b}=1.16 \times 10^{-4} \mathrm{~m}$, which is comparable to the assumed initial aperture for the ROCMAS simulations. In addition, $b$ is of reasonable magnitude for a fracture created by hydraulic stimulation (e.g. see Yeo et al., 1998; Murphy et al., 1999).

The model illustrated in Fig. 6 shows that flow in the reservoir is mainly controlled by a large fracture during the injection/shut-in phases, whereas fracture-matrix flow is dominant during the production/shut-in phases. This observation is of practical relevance for the exploitation of geothermal energy from tight sedimentary formations. A proper understanding of the hydromechanical behaviour of fractures helps to optimize injection and production flow rates in order to maximize productivity. For example, injection with high flow rates ensures an open 
fracture of high conductivity through which massive water volumes can circulate and thereby pick up heat from the surrounding formation.

Reservoir pressure levels determine the best locations from which fluids should be extracted. Applying the huff-puff concept at specific test sites could show that injection and production may affect different parts of the reservoir.

\section{Final Remarks}

Although the previous analysis showed that hydromechanical processes influence flow behaviour in a stimulated reservoir, their effect on thermal efficiency was not studied. It remains unclear if cold-water injection into a large fracture and hot-water production from a different part of the reservoir decreases its commercial or productive lifetime.

The simulation results obtained from ROCMAS are not unique, so that a different set of parameters may result in very similar computed pressure behaviour. A sensitivity study needs to be done in order to investigate the influence of different parameters on the modelling results. Even more precise results could be obtained by 3D simulations including a (linear) Detfurth fracture and a larger fracture that opens at sufficiently high injection pressure.

A further issue to be addressed in future work is the investigation of hydromechanical response of fractures located in different types of rock masses. Fractures behave differently in the sandstone (Detfurth) and the claystone formations. Whereas the fracture in the Detfurth remains permanently open, the one in the claystone layers responds to hydromechanical effects.

The analysis presented above gives insight into fluid leakage during shut-in. If the reservoir is permanently cooled due to the extraction of geothermal heat, thermal shrinkage of the formation may affect the long-term behaviour of the leakage through the development of secondary fractures directed normal to the fracture created by hydraulic stimulation. Thus, a series of huff-puff tests may give insight into such processes over longer geothermal energy production periods. Furthermore, the influence of thermal formation shrinkage on the deformation of the large-scale fracture needs to be studied. At present, it is not clear whether the cooling of the fracture surfaces results in a significant opening of the fracture, which would influence the rate of geothermal energy extraction.

Finally, the effect of the injection flow rate on the hydromechanical fracture behaviour needs further investigation. It is likely that flow behaviour within the reservoir will change with injection rate, as has already been shown by the low-injection rate test (Fig. 5). Analysis of additional injection/shut-in experiments using different flow rates would give us a better understanding of the response of 3D fractures to hydromechanical processes.

\section{Acknowledgements}

We acknowledge financial support by the Federal Ministry for the Environment, Nature Conversation and Nuclear Safety (BMU, Germany), Grant No. 0329995 and by the U.S. Dept. of Energy under Contract No. DE-AC02-05CH11231. We also thank the initiators of the GeneSys project, Dr. R. Jung and Dr. J. Orzol. Finally, the analysis could not have been performed without the experimentalists who carried out the tests, whom we also acknowledge. 


\section{References}

Biot, M.A., 1941. General theory of three dimensional consolidation. J. Applied Physics 12, 155-164.

Biot M.A. and Willis, D.G., 1957. The elastic coefficients of the theory of consolidation. Journal of Applied Mechanics 24, 594-601.

Bourdarot, G., 1998. Well Testing: Interpretation Methods, Editions Technip, Paris, France, 350 pp.

Brenner, S.L., Gudmundsson, A., 2002. Permeability development during hydrofracture propagation in layered reservoirs. NGU Bulletin 439, 71-77.

Craig, D.P., 2006. Analytical modelling of a fracture-injection/falloff sequence and the development of a refracture-candidate diagnostic test. Ph.D. thesis, Texas A\&M University, College Station, TX, USA, $281 \mathrm{pp}$.

Garg, S.K., Nur, A., 1973. Effective stress laws for fluid-saturated porous rocks. Journal of Geophysical Research 78, 5911-5921.

Ghassemi, A., Kumar, G. S., 2007. Changes in fracture aperture and fluid pressure due to thermal stress and silica dissolution/precipitation induced by heat extraction from subsurface rocks.

Geothermics 36, 115-140

Goodman, R.E., 1974. The mechanical properties of joints. In: Proceedings of the 3rd Int Congress International Society of Rock Mechanics, Denver, CO, USA. National Academy of Sciences, Washington, DC, USA, Vol. I, pp. 127-140.

Gordeyev, Y.N., Zazovsky, A.F., 1992. Self-Similar Solution for Deep-Penetrating Hydraulic Fracture Propagation. Transport in Porous Media 7, 283-304.

Gudmundsson, A., Fjeldskaar, I., Brenner, S.L., 2002. Propagation pathways and fluid transport of hydrofractures in jointed and layered rocks in geothermal fields. Journal of Volcanology and Geothermal Research 116, 257- 278.

Jaeger, J.C., Cook, N.G.W., Zimmermann, R.W., 2007. Fundamentals of Rock Mechanics. $4^{\text {th }}$ ed. Blackwell Publishing Ltd, Malden, Oxford, 475 pp.

Kulhawy, F.H., 1975. Stress deformation properties of rock and rock discontinuities. Engineering Geology 9, 327-350.

Legarth, B., Huenges, E., Zimmermann, G., 2005. Hydraulic fracturing in a sedimentary geothermal reservoir: Results and implications. Int. J. Rock Mech. Min. Sci. 42, 1028-1041.

Lizak, K., Barto, K., Self, F., Izquierdo, G., Al-Mumen, M., 2006. New analysis of step-rate injection tests for improved fracture stimulation design. Saudi Aramco Journal of Technology, Spring 2006, 7-17.

Matsuki, K., Chida, Y., Sakaguchi, K., Glover, P.W.J., 2006. Size effect on aperture and permeability of a fracture estimated in large synthetic fractures. Int. J. Rock Mech. Min. Science 43, 726-755.

Megél, T., Kohl, T., Hopkirk, R.J., 2006. The potential of the use of dense fluids for initiating hydraulic stimulation. Geothermics 35, 589-599.

Min, B.K., Rutqvist, J., Tsang, C.F., Jing, L., 2004. Stress-dependent permeability changes of fractured rock masses: a numerical study. Int. J. Rock Mech. Min. Sci. 41, 1191-1210. 
MIT, 2006. The future of Geothermal Energy. Massachusetts Institute of Technology, Cambridge, Massachusetts, U.S.A., $372 \quad$ pp. http://geothermal.inel.gov/publications/future_of_geothermal_energy.pdf

Murphy, H., Brown, D., R, J., Matsunaga, I., Parker, R., 1999. Hydraulics and well testing of engineered geothermal reservoirs. Geothermics 28, 491-506.

Nolte, K.G., 1979. Determination of fracture parameters from fracturing pressure decline. SPE paper 8341 presented at the SPE $54^{\text {th }}$ Annual Fall Technical Conference and Exhibition, Las Vegas, NV, USA, 16 pp.

Noorishad, J., Tsang, C.-F., Witherspoon, P. A., 1992. Theoretical and field studies of coupled behaviour of fractured rocks - 1. Development and verification of a numerical simulator. Int. J. Rock Mech. Min. Sci. \& Geomech. Abstr. 29, 401-409.

Nur, A., Byerlee, J.D., 1971. An exact effective stress law for elastic deformation of rock with fluids. Journal of Geophysical Research 76, 6414-6419.

Olsson, W. A., Brown, S.R., 1993. Hydromechanical response of a fracture undergoing compression and shear. Int. J. Rock Mech. Min. Sci. \& Geomech. Abstr. 30, 845-851.

Orzol, J., Jatho, R., Jung, R., Kehrer, P., Tischner, T., 2004. The GeneSys Project - Development of concepts for the extraction of heat from tight sedimentary rocks. Z. Angew. Geol. 2, 17-23.

Röhling, H. G., 1991. A lithostratigraphic subdivision of the lower Triassic in the Northwest German Lowlands and the German Sector of the North Sea, based on Gamma-Ray and Sonic Logs. Geologisches Jahrbuch A 119, 3-23.

Rutqvist, J., 1995. Determination of hydraulic normal stiffness of fractures in hard rock from hydraulic well testing. Int. J. Rock Mech. Min. Sci. \& Geomech. Abstr. 32, 513-523.

Rutqvist, J., Börgesson, L., Chijimatsu, M., Nguyen, T.S., Jing, L., Noorishad, J., Tsang, C.-F., 2001. Coupled thermo-hydro-mechanical analysis of a heater test in fractured rock and bentonite at Kamaishi Mine - Comparison of field results to predictions of four finite element codes. Int. J. Rock Mech. \& Min. Sci. 38,129-142.

Rutqvist, J., Noorishad, J., Stephansson, O., and Tsang, C.-F., 1992. Theoretical and field studies of coupled hydromechanical behaviour of fractured rocks -2 . Field experiment and modelling. Int. J. Rock Mech. Min. Sci. \& Geomech. Abstr. 29, 411-419.

Rutqvist, J., Noorishad, J., Tsang, C.-F., Stephansson, O., 1998. Determination of fracture storativity in hard rocks using high-pressure injection tests. Water Resources Research 34, 2551-2560.

Rutqvist, J., Stephansson, O., 2003. The role of hydromechanical coupling in fractured rock engineering. Hydrogeology Journal 11, 7-40.

Sausse, J., 2002. Hydromechanical properties and alteration of natural fracture surfaces in the Soultz granite (Bas-Rhin, France). Tectonophysics 348, 169-185.

Silin, D.B., Patzek, T.W., 2001. Water injection into a low-permeability rock - 2: Control model. Transport in Porous Media 43, 557-580.

Silin, D.B., Tsang, C.-F., 2002. Estimation of formation hydraulic properties accounting for pre-test injection or production operations. Journal of Hydrology 265, 1-14. 
Singh, P. K., Agarwal, R. G., Krase, L. D., 1987. Systematic design and analysis of step-rate tests to determine formation parting pressure. SPE paper 16798 presented at $62^{\text {nd }}$ Annual Technical Conference and Exhibition of the Society of Petroleum Engineers, Dallas, TX, USA, Sept 27-30, 1987, pp. 491503.

Sulzbacher, H., Jung, R., 2004. Modellprognosen zum Wärmetauscher Horstberg Z1. Unpublished report, Leibniz Institute for Applied Geosciences, Hannover, Germany, Archive No. 0127516, 32 pp.

Tischner, T., Sulzbacher, H., Jung, R., Jatho, R., Kehrer, P., 2004. GeneSys: Hydraulische und thermische Charakterisierung des künstlich erzeugten Risses und Implikationen für dessen geothermische Nutzung. Tagungsband 8. Goethermische Fachtagung, Landau, Germany, 10-12 Nov. 2004, 131-139.

Valko, P., Economides, M.J., 1997. Hydraulic Fracture Mechanics. John Wiley \& Sons, New York, NY, USA, 318 pp.

Wallroth, T., Eliasson, T., Sundquist, U., 1999. Hot dry rock research experiments at Fjällbacka, Sweden. Geothermics 28, 617-625.

Warpinski, N.R., Teufel, L.W., 1987. Influence of geologic discontinuities on hydraulic fracture propagation. Journal of Petroleum Technology 39 (2), 209-220.

Wessling, S., Backers, T., Junker, R., Tischner, T., 2008. Stress determination and associated analysis from pressure records during the Detfurth hydraulic stimulation (Horstberg Z1, 2004). Unpublished report, Leibniz Institute for Applied Geosciences, Hannover, Germany, Archive No. 0127547, 22 pp.

Witherspoon, P.A., Amick, C.H., Gale, J.E., Iwai, K., 1979. Observations of a potential size effect in experimental determination of the hydraulic properties of fractures. Water Resources Research 15, 1142 1146.

Witherspoon, P.A., Wang, J.S.Y., Iwai, K., Gale, J.E., 1980. Validity of cubic law for fluid flow in a deformable rock fracture. Water Resources Research 16, 1016-1024.

Yeo, I.W., De Freitas, M.H., Zimmermann, R.W., 1998. Effect of shear displacement on the aperture and permeability of a rock fracture. Int. J. Rock Mech. Min. Sci. 35, 1051-1070. 


\section{Tables}

Table 1

Output obtained from curve fitting with ODA when $\mathrm{t}_{0}=0 \mathrm{~h}, \mathrm{t}_{1}=0.05 \mathrm{~h}$, and $\mathrm{t}_{2}=1.8 \mathrm{~h}$ (linear flow model), and $\mathrm{t}_{0}=2 \mathrm{~h}, \mathrm{t}_{1}=3 \mathrm{~h}$, and $\mathrm{t}_{2}=20 \mathrm{~h}$ (radial flow model).

\begin{tabular}{|c|c|c|c|c|}
\hline Parameter & Symbol & Units & Value (linear) & Value (radial) \\
\hline History source * & Qhist & $\mathrm{L} / \mathrm{s}$ & 0.2 & 11.8 \\
\hline Real injection rate* & $\mathrm{Q}$ & $\mathrm{L} / \mathrm{s}$ & 0. & 19.6 \\
\hline Skin & Sk & - & 0.488 & 0.075 \\
\hline Factor & $\mathrm{F}$ & $\mathrm{Pa} \cdot \mathrm{s}^{1 / 2} / \mathrm{m}^{3}$ & $5.4 \times 10^{6}$ & - \\
\hline Transmissivity & $\mathrm{T}$ & $\mathrm{m}^{3} / \mathrm{Pa} \cdot \mathrm{s}$ & - & $4.42 \times 10^{-10}$ \\
\hline Storativity & $\mathrm{S}$ & $\mathrm{m} / \mathrm{Pa}$ & - & $8.6 \times 10^{-3}$ \\
\hline
\end{tabular}

* rate prior to $t_{1}$

Table 2

Values obtained from fitting pressures observed during the injection phase.

\begin{tabular}{|l|c|l|l|}
\hline \multicolumn{1}{|c|}{ Parameter } & Symbol & \multicolumn{1}{c|}{ Units } & \multicolumn{1}{c|}{ Value } \\
\hline Initial constant factor & $\mathrm{X}_{0}$ & $1 / \sqrt{\mathrm{sm}^{3}}$ & $1.75 \times 10^{10}$ \\
\hline Pre-exponential factor at injection & $\beta_{\mathrm{i}}$ & $1 / \mathrm{s}$ & $5.26 \times 10^{-3}$ \\
\hline Exponent at injection & $\gamma_{\mathrm{i}}$ & - & 0.48 \\
\hline Relative error at injection* & $\delta \mathrm{r}_{1}$ & $\mathrm{MPa}$ & $1.38 \times 10^{-4}$ \\
\hline $\begin{array}{l}\text { Time-dependent factor at end of injection } \\
\text { (shut-in start) }\end{array}$ & $\mathrm{X}_{\mathrm{s}}$ & $1 / \sqrt{\mathrm{sm}^{3}}$ & $6.97 \times 10^{9}$ \\
\hline
\end{tabular}

* The relative error between measurements and calculated pressures was calculated according to $\delta_{r}=\sqrt{1 / n \sum_{i=1}^{n}\left(\Delta p_{i}\right)^{2}}$ ( $\mathrm{n}$ is the number of pressure samples) 
Table 3

Fracture (top table) and matrix (lower table) parameters for which the simulation results could be fitted to the measured downhole pressures. For comparison purposes the parameters obtained from fitting the injection phase by assuming a linear model are also presented. Subscripts $f$ and $m$ denote the fracture and matrix, respectively.

\begin{tabular}{|l|l|l|l|c|}
\hline \multicolumn{1}{|c|}{ Fracture Parameter } & \multicolumn{1}{c|}{ Symbol } & \multicolumn{1}{c|}{ Units } & Value (radial) & Value (linear) \\
\hline Fracture half length (linear flow) & $\mathrm{x}_{\mathrm{f}}$ & $\mathrm{M}$ & - & 2000 \\
\hline Fracture radius (radial flow) & $\mathrm{r}$ & $\mathrm{M}$ & 260 & - \\
\hline Fracture normal stiffness & $\mathrm{K}_{\mathrm{n}}$ & $\mathrm{Pa} / \mathrm{m}$ & - & $5.0 \times 10^{11}$ \\
\hline Initial fracture aperture 1 & $b_{0}^{1}$ & $\mathrm{M}$ & $2 \times 10^{-4}$ & $7.6 \times 10^{-4}$ \\
\hline Initial fracture aperture 2 & $b_{0}^{2}$ & $\mathrm{M}$ & $10^{-5}$ & $7.6 \times 10^{-4}$ \\
\hline Initial effective normal stress fracture 1 & $\sigma_{n 0}^{1}$ & $\mathrm{MPa}$ & -10 & - \\
\hline Initial effective normal stress fracture 2 & $\sigma_{n 0}^{2}$ & $\mathrm{MPa}$ & -5 & - \\
\hline Biot's constant & $\alpha_{\mathrm{f}}$ & - & 1 & 1 \\
\hline Biot's modulus & $\mathrm{M}_{\mathrm{f}}$ & $\mathrm{GPa}$ & 1.3 & 2.3 \\
\hline Minimum residual aperture 1 & $b_{\text {res }}^{1}$ & $\mathrm{M}$ & $10^{-5}$ & - \\
\hline Minimum residual aperture 2 & $b_{\text {res }}^{2}$ & $\mathrm{M}$ & $10^{-5}$ & - \\
\hline
\end{tabular}

\begin{tabular}{|l|l|l|c|c|}
\hline \multicolumn{1}{|c|}{ Matrix Parameter } & \multicolumn{1}{c|}{ Symbol } & \multicolumn{1}{c|}{ Units } & Value (radial) & Value (linear) \\
\hline Rock density & $\rho_{\mathrm{m}}$ & $\mathrm{kg} / \mathrm{m}^{3}$ & 2890 & 2890 \\
\hline Rock permeability & $\mathrm{k}_{\mathrm{m}}$ & $\mathrm{m}^{2}$ & $1 \times 10^{-18}$ & $5.0 \times 10^{-15}$ \\
\hline Rock porosity & $\Phi$ & - & 0.05 & 0.05 \\
\hline Young's modulus & $\mathrm{E}$ & $\mathrm{GPa}$ & 25 & 15 \\
\hline Poisson ratio & $\mathrm{V}$ & - & 0.25 & 0.25 \\
\hline Biot's constant & $\alpha_{\mathrm{m}}$ & - & 1 & 1 \\
\hline Biot's modulus & $\mathrm{M}_{\mathrm{m}}$ & $\mathrm{GPa}$ & 44 & 44 \\
\hline
\end{tabular}


Figures

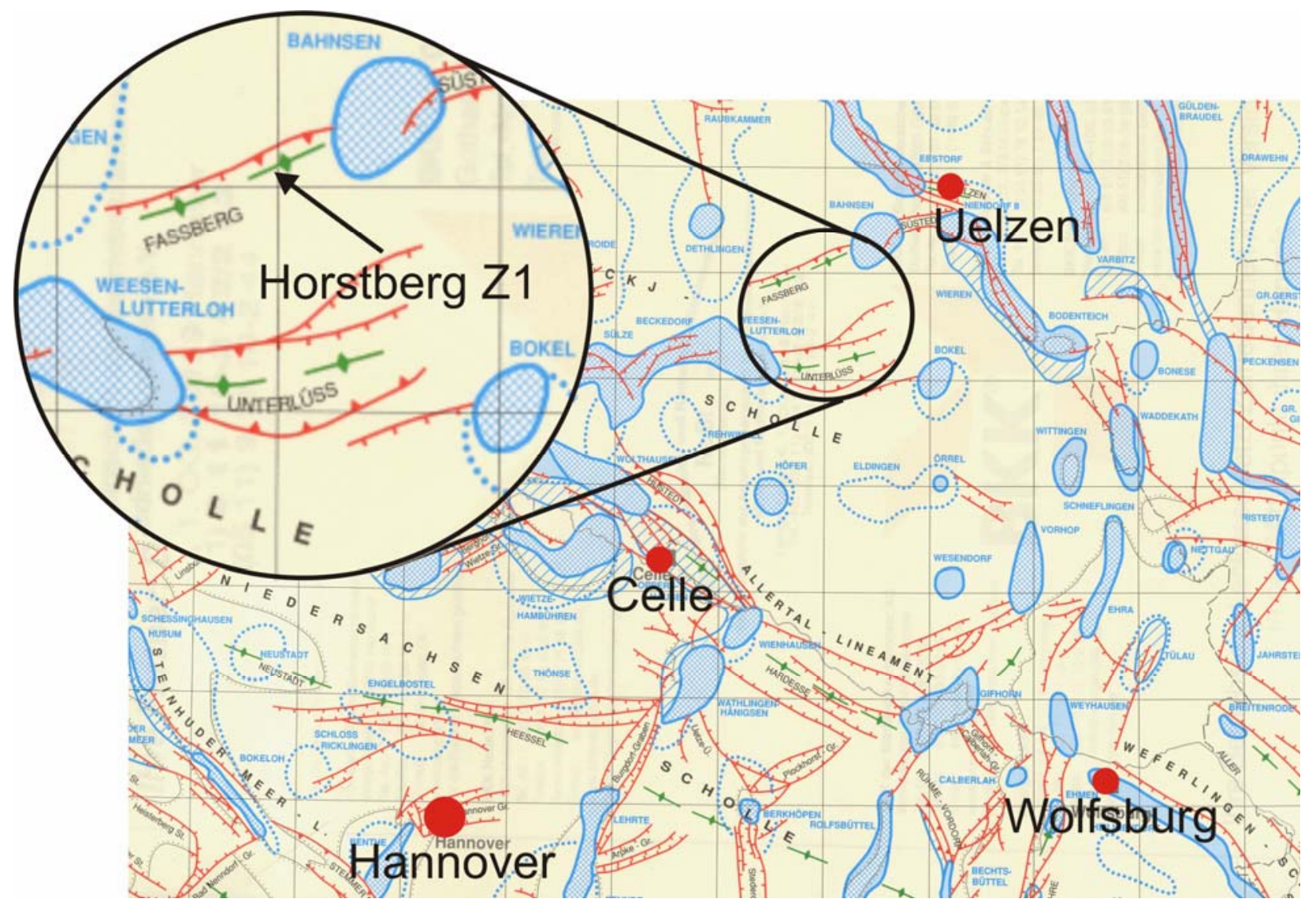

Fig. 1. Location of the test well Horstberg Z1 in Lower Saxony, Germany. The site is situated in an anticlinal structure called "Fassberg Struktur" that was formed by the forces caused by the uplift of adjacent salt domes (shaded areas) (Orzol et al., 2004). 


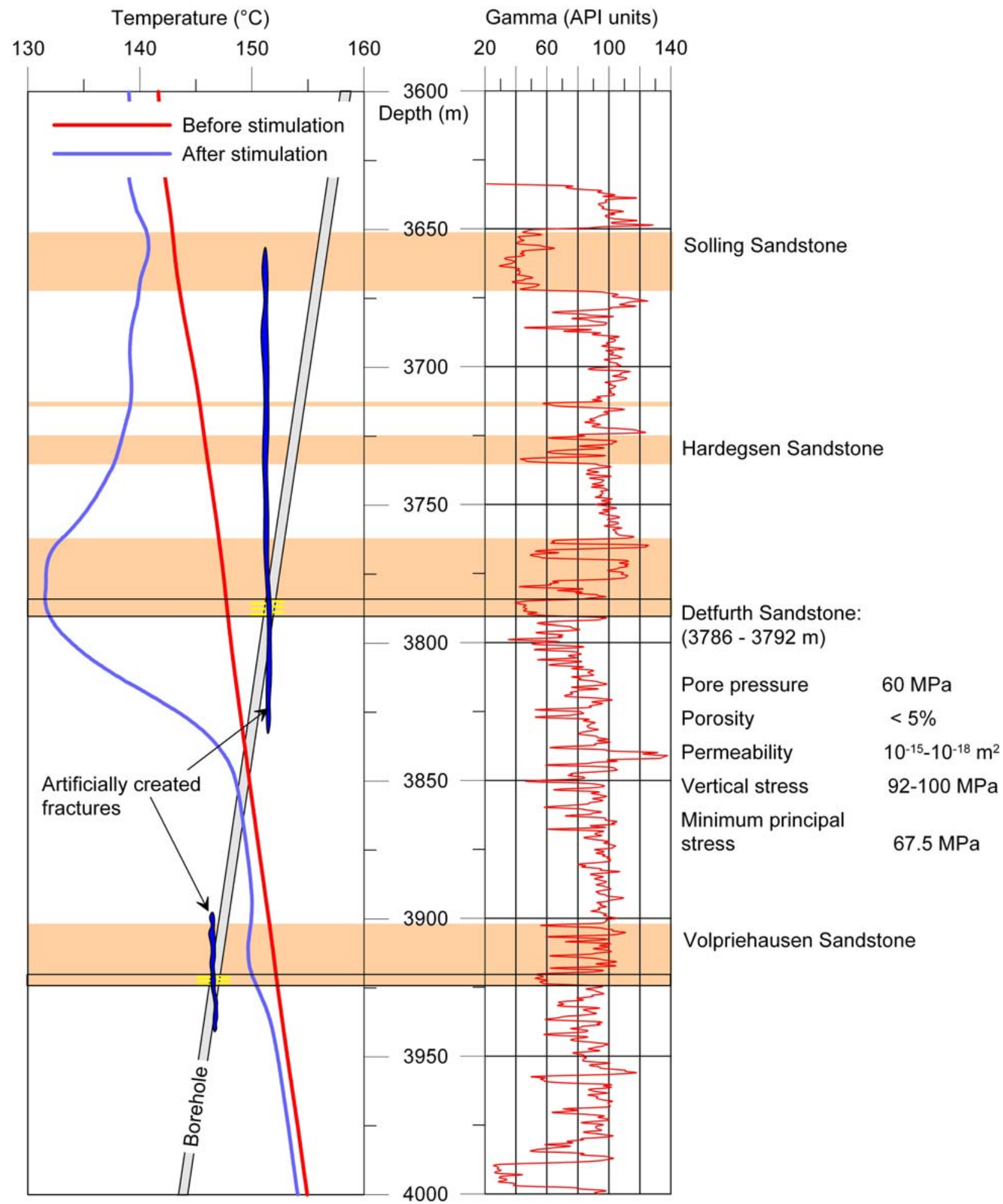

Fig. 2. Some of the subsurface information collected in borehole Horstberg Z1. For the geology of the Middle Bunter see Röhling (1991), and for reservoir characteristics of the Detfurth Sandstone see Orzol et al. (2004) and Wessling et al. (2008). 


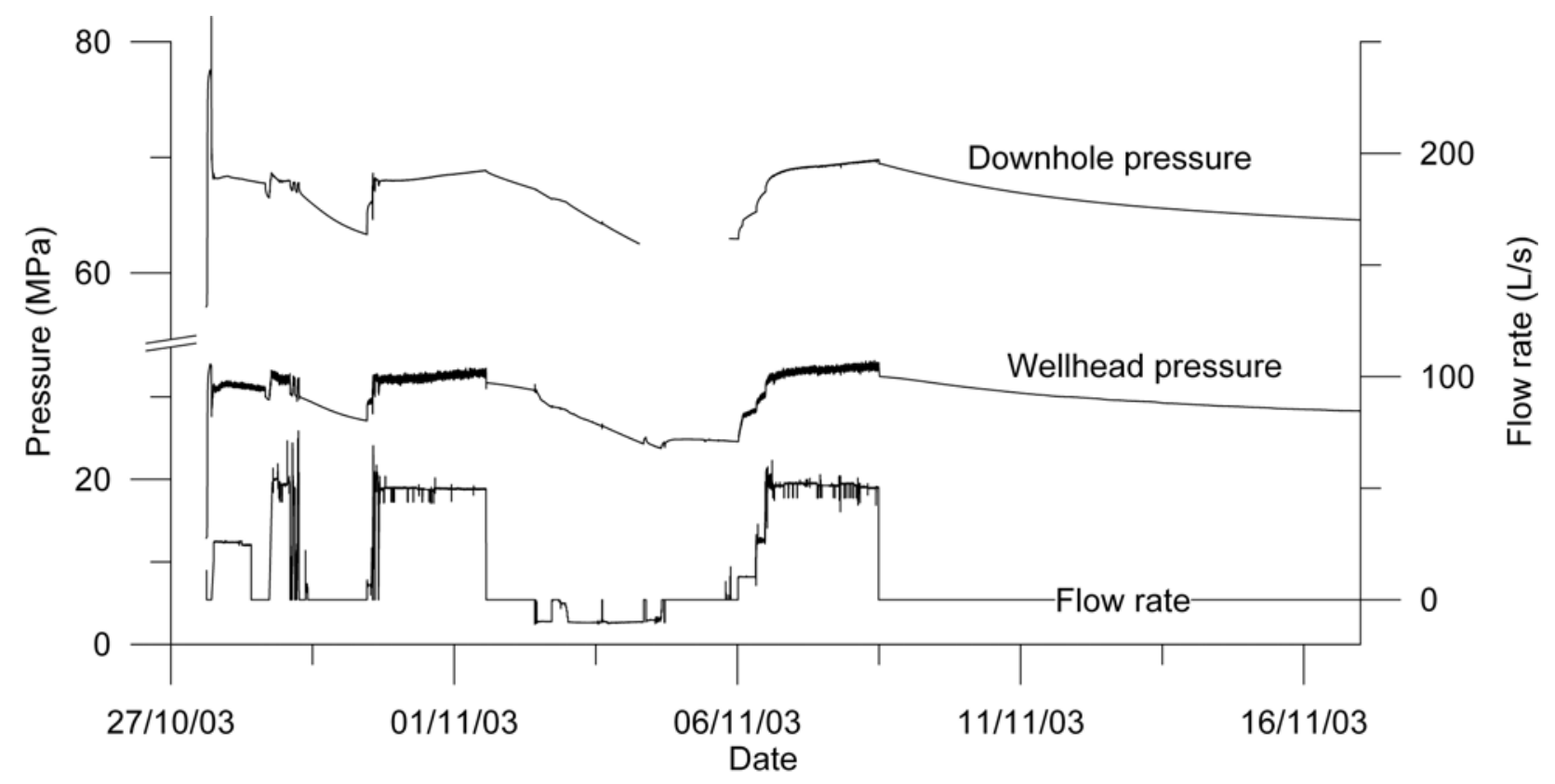

Fig. 3. Pressure and flow rate recorded during the 2003 hydraulic stimulation of the Detfurth Sandstone.

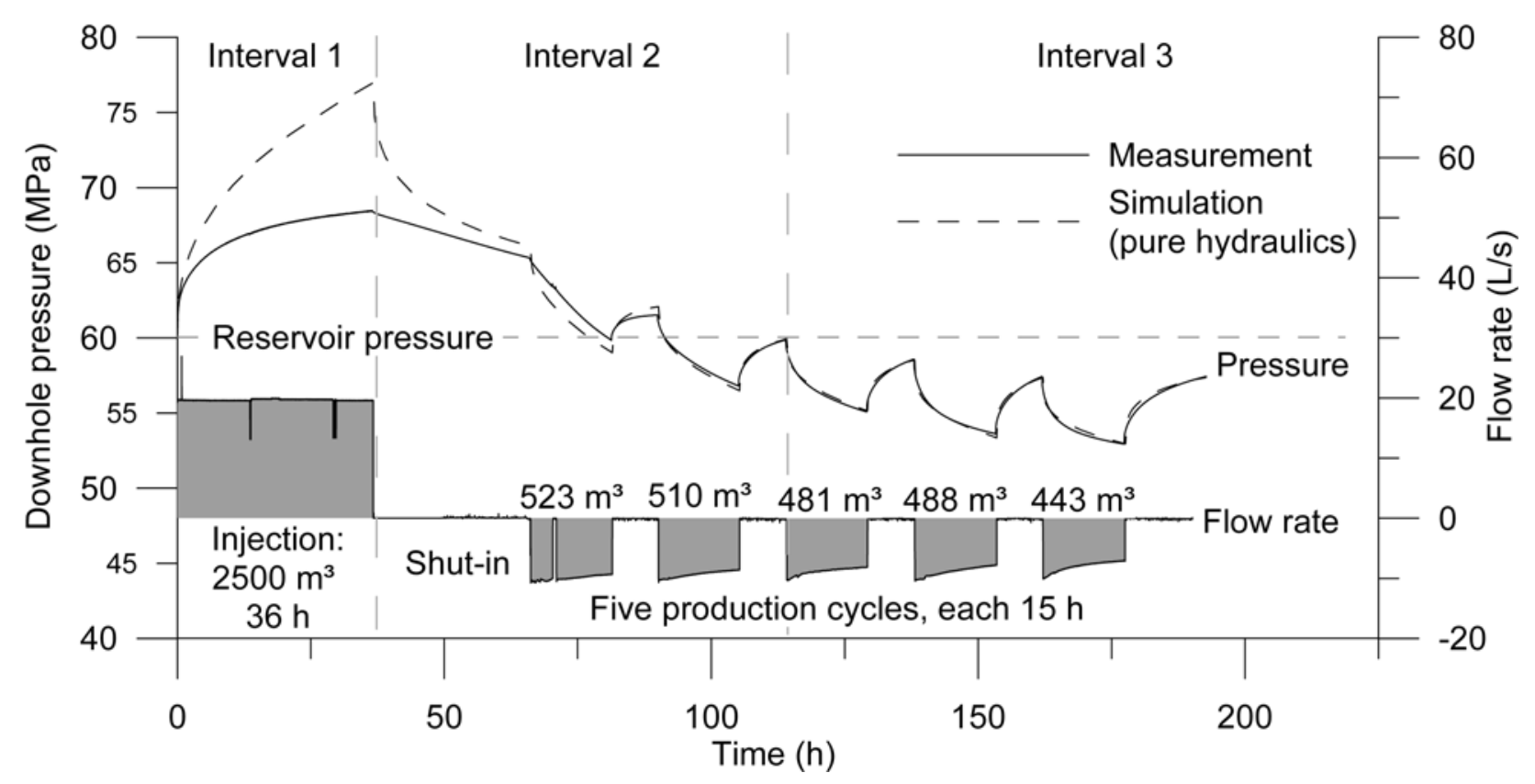

Fig. 4. Data from the huff-puff test performed in February 2004. The division into three intervals refers to the simulation study done by Sulzbacher and Jung (2004). 


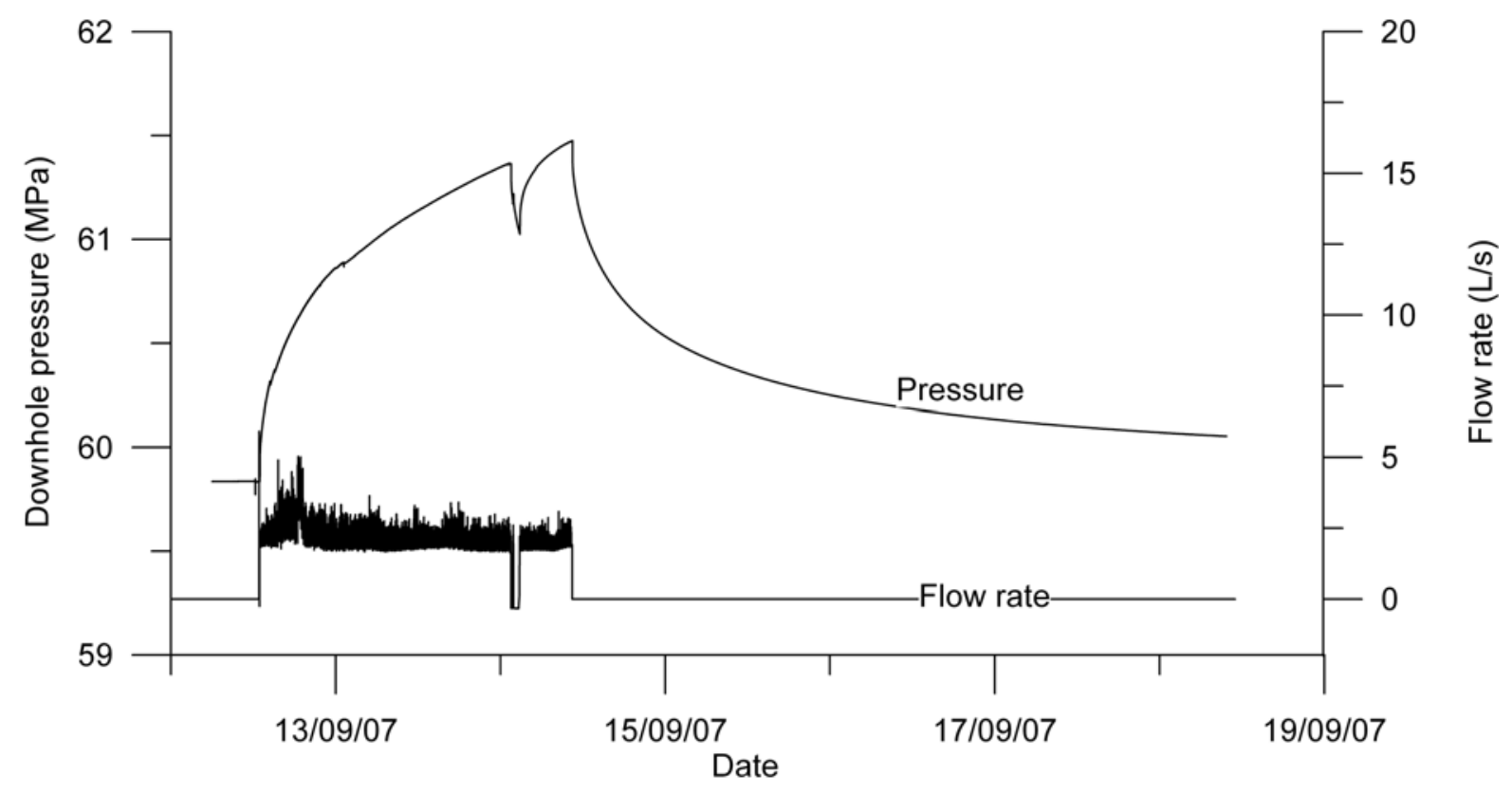

Fig. 5. Injection/shut-in hydraulic test performed in September 2007. Shown are downhole pressures and temperatures measured at $3800 \mathrm{~m}$ depth. Injection rate was about $2 \mathrm{~L} / \mathrm{s}$.
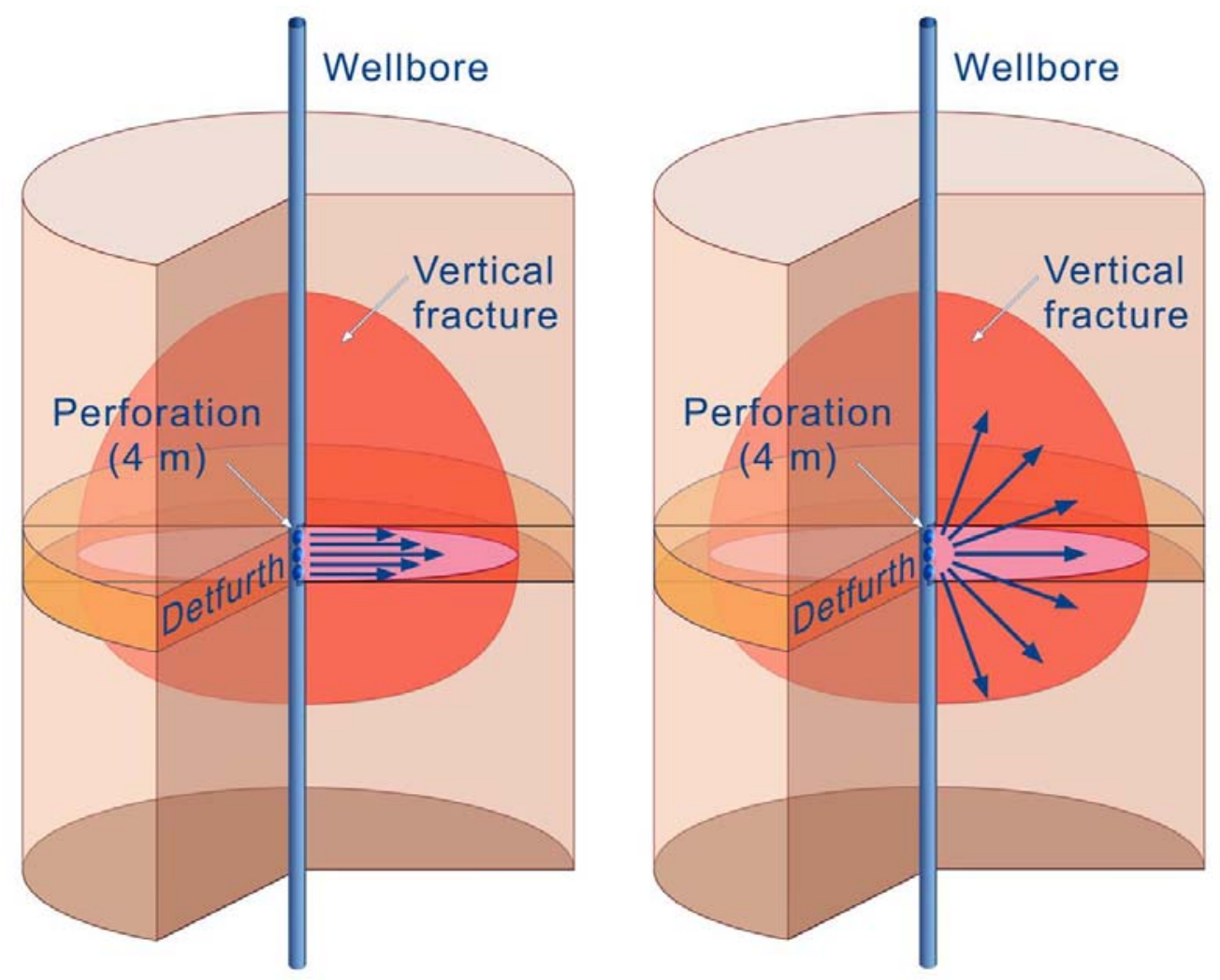

Fig. 6. Illustration showing the change in flow behaviour during the February 2004 huff-puff test. Left: early linear flow occurring only in the Detfurth Sandstone; right: radial flow taking place in the entire fracture after its opening. 


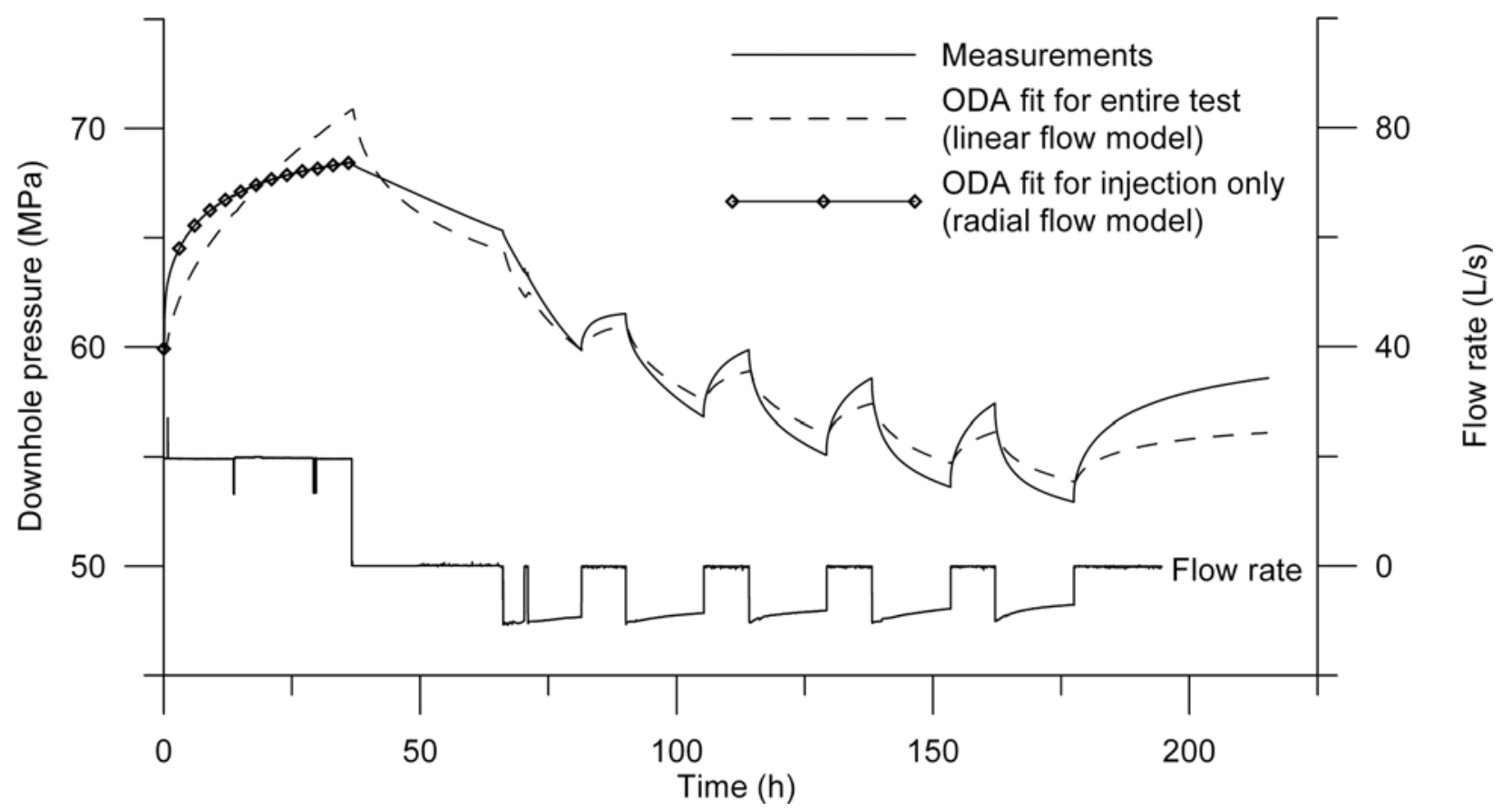

Fig. 7. Results of fitting pressures measured during February 2004 huff-puff test using the code ODA.

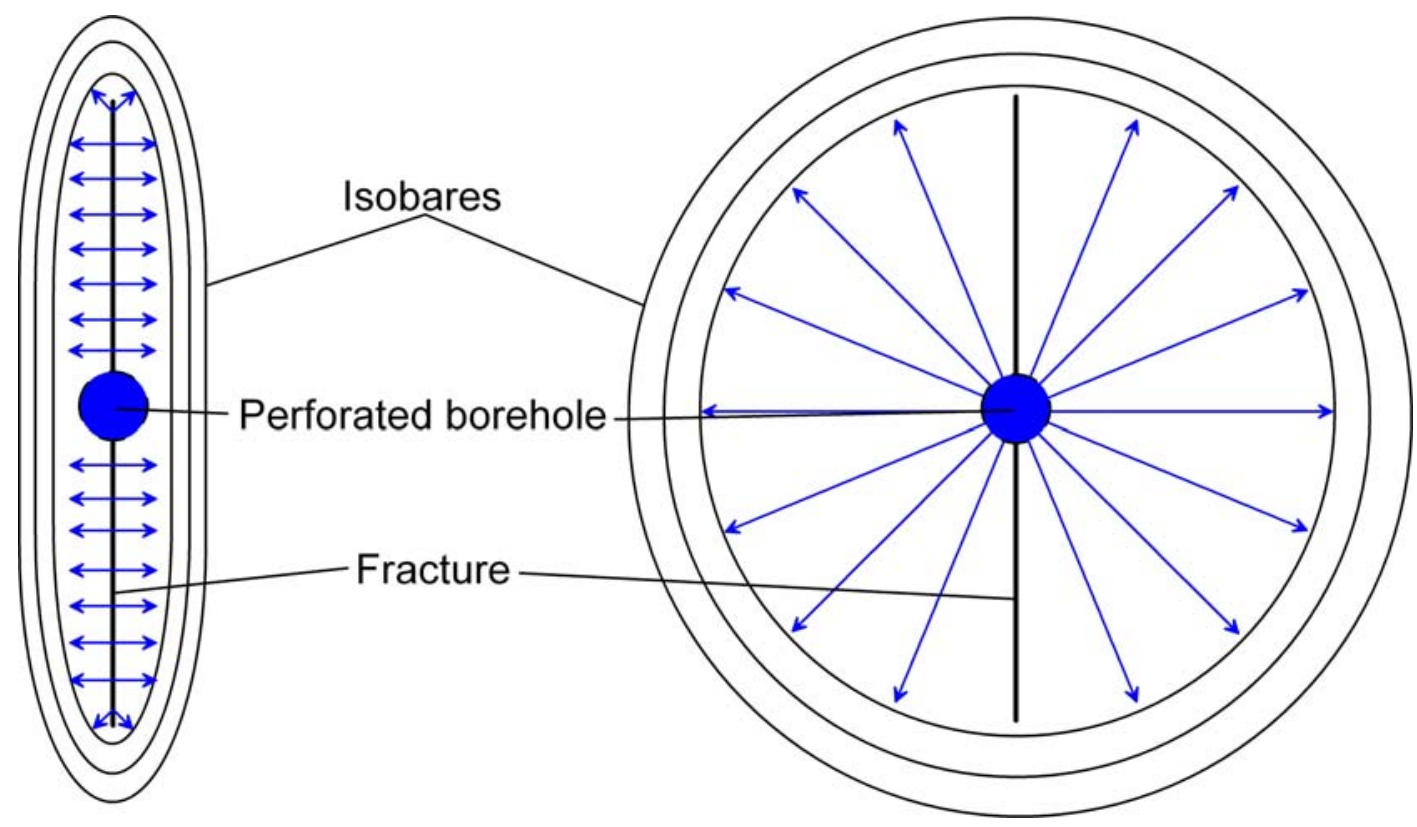

Fig. 8. Schematic illustration (top view) of the pressure distribution and the associated predominant flow pattern that develops at an early injections stage (left: formation linear flow) and after a long injection (right: pseudo-radial flow). 


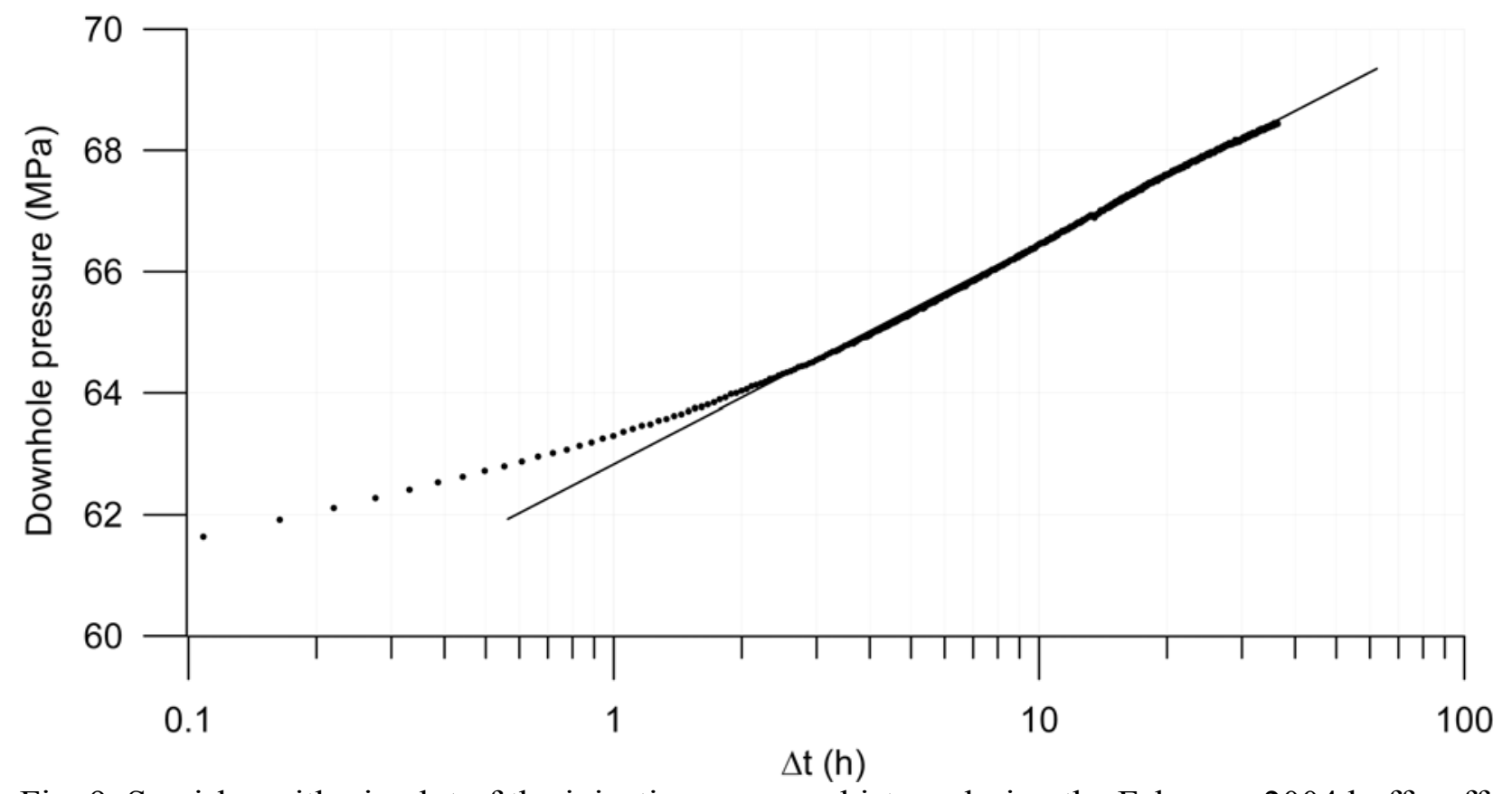

Fig. 9. Semi-logarithmic plot of the injection pressure history during the February 2004 huff-puff test, showing a linear slope after 2 hours. $\Delta \mathrm{t}$ is the time increment from the start of injection.

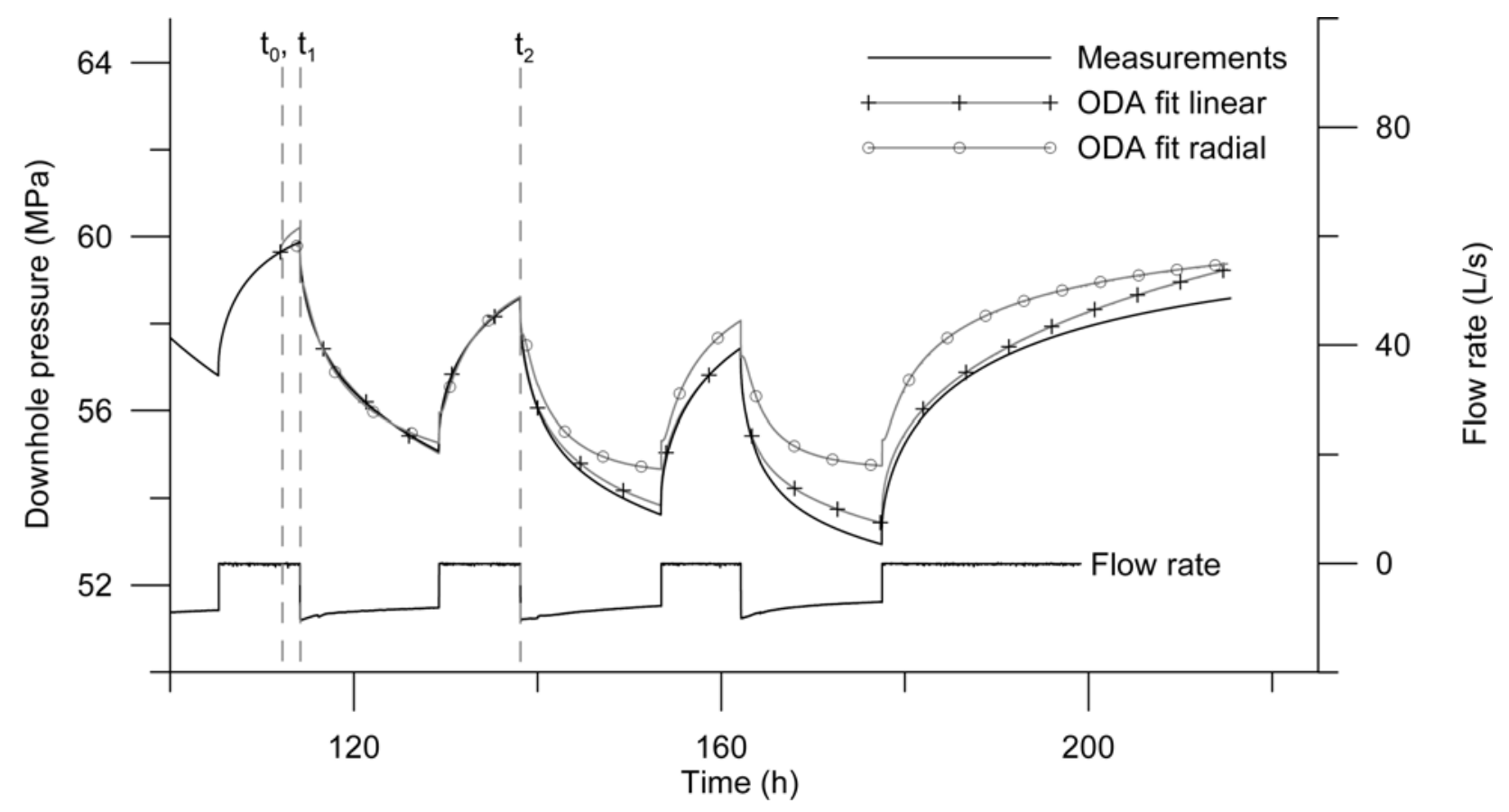

Fig. 10. ODA fits to pressures measured during the February 2004 huff-test assuming linear and radial flow models. 


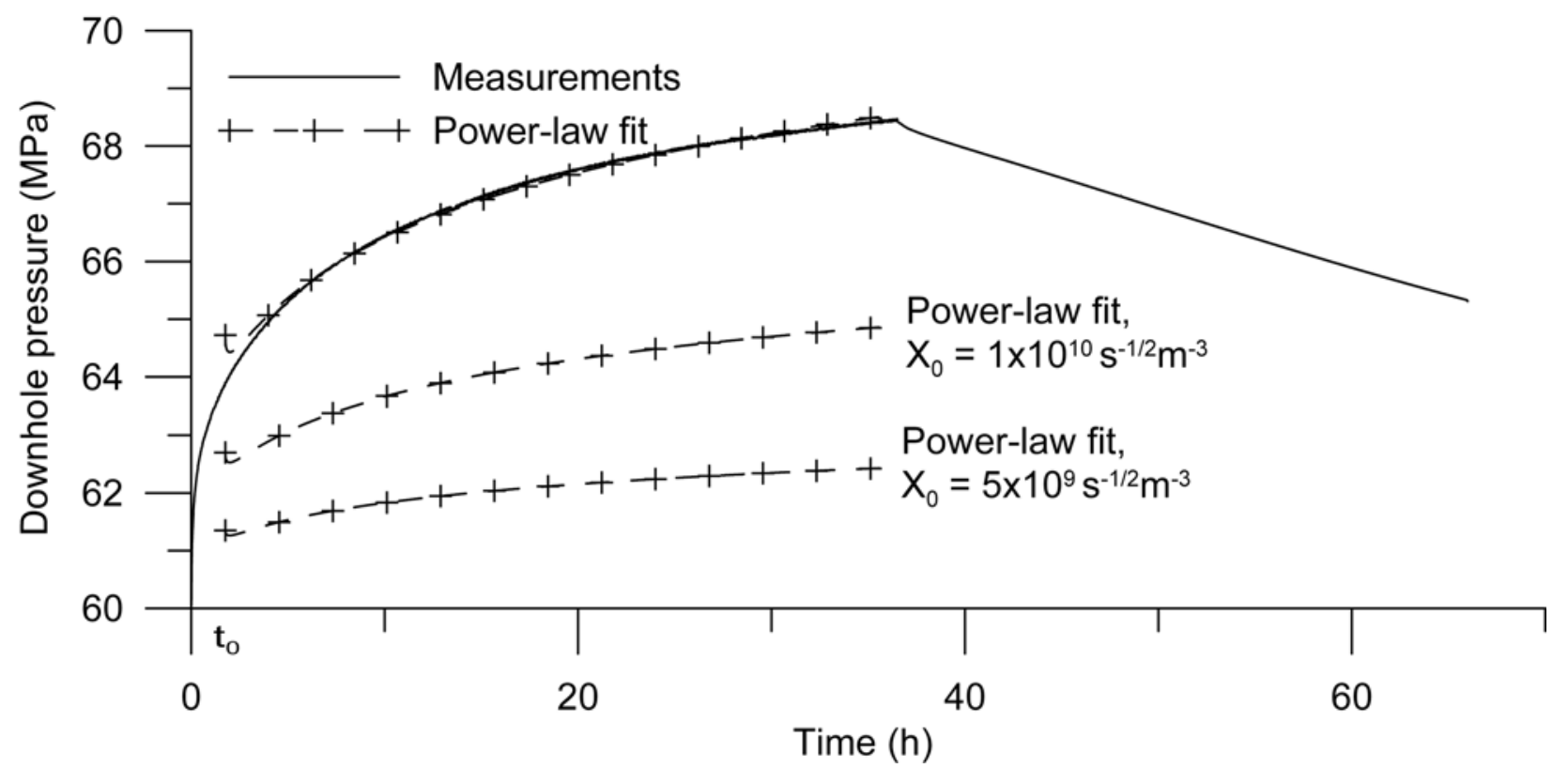

Fig. 11. Fit to pressures measured during the February 2004 huff-puff test using the analytical solution.
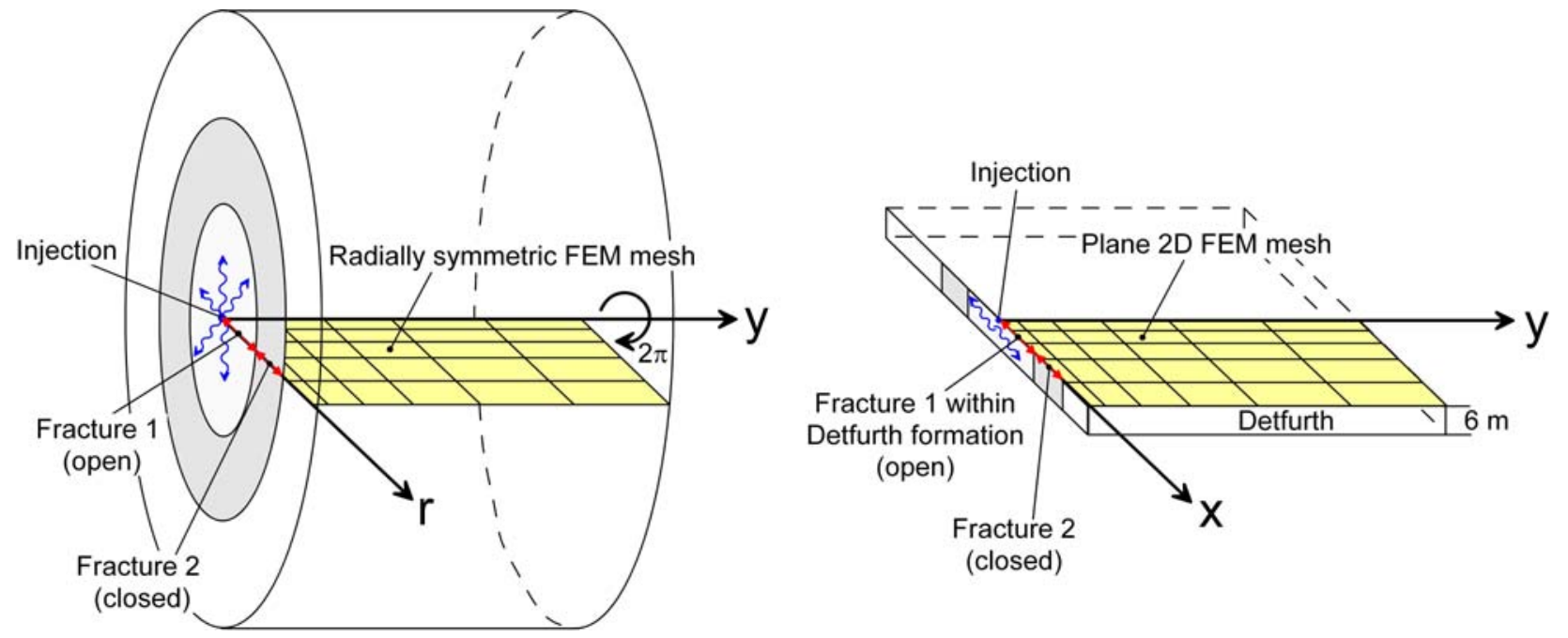

Fig. 12. Model setup for radial (left) and linear (right) flow simulations. 


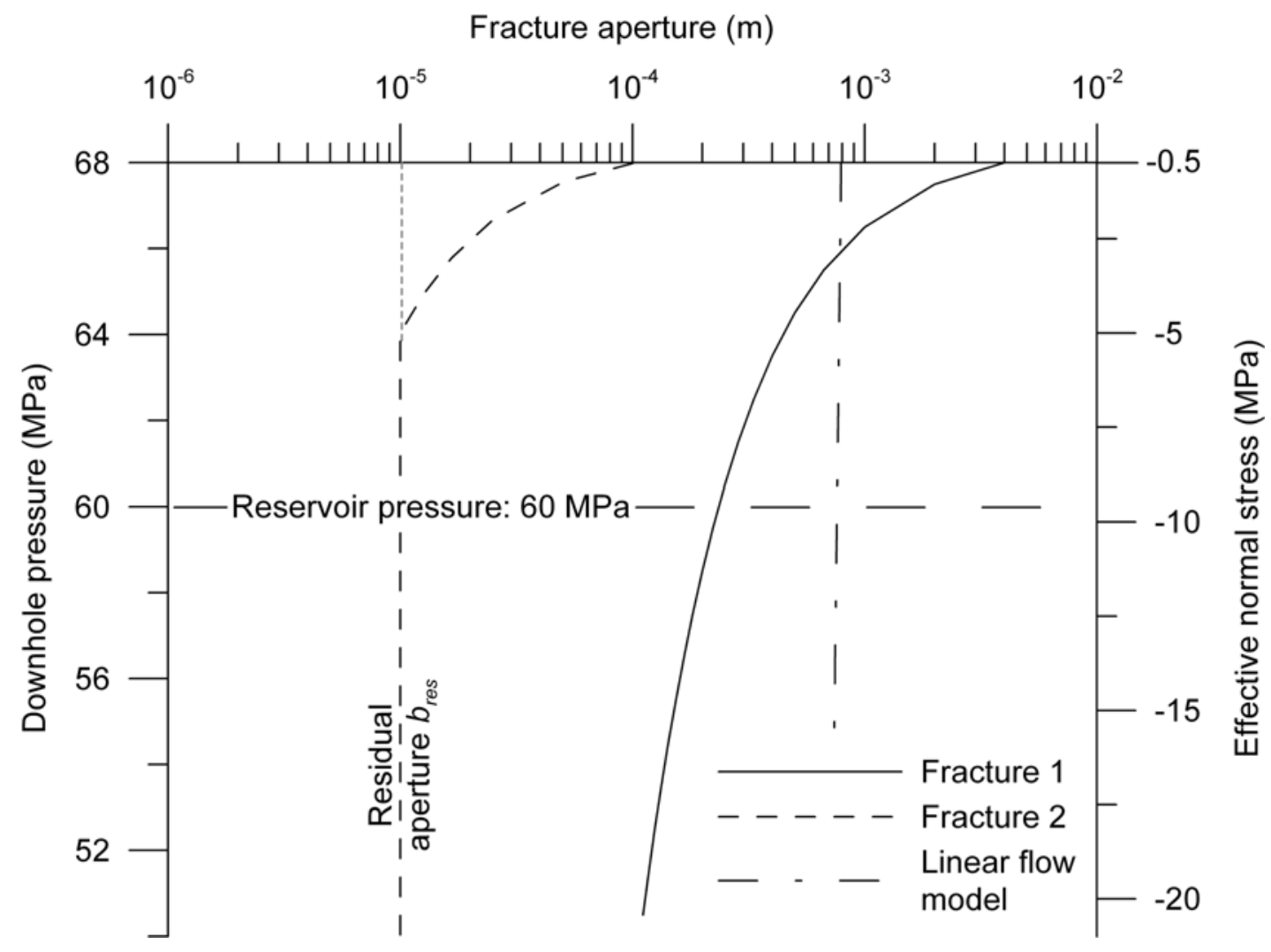

Fig. 13. Apertures of Fractures 1 and 2 as a function of effective normal stress (see Eq. 21). For the assumed closure pressure of $\sigma_{\mathrm{n}}=68.5 \mathrm{MPa}$, the apertures corresponding to the effective normal stress at reservoir pressure and lowest production pressure are indicated.

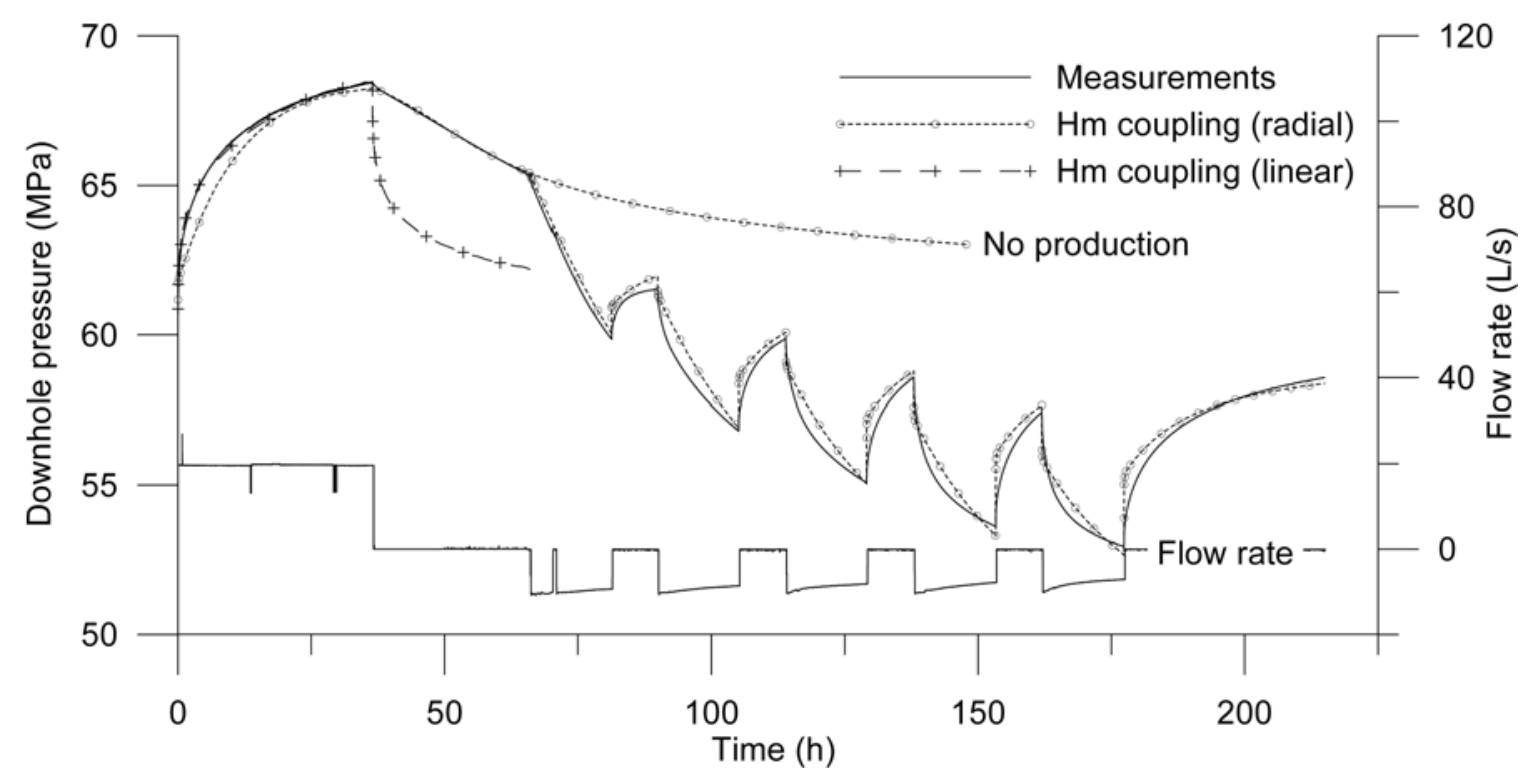

Fig. 14. February 2004 huff-puff test. Fit between computed and measured pressures using the code ROCMAS. Parameters for simulation are given in Table 3. Simulations have been performed assuming linear and a radial flow models. Hm: hydromechanical. 

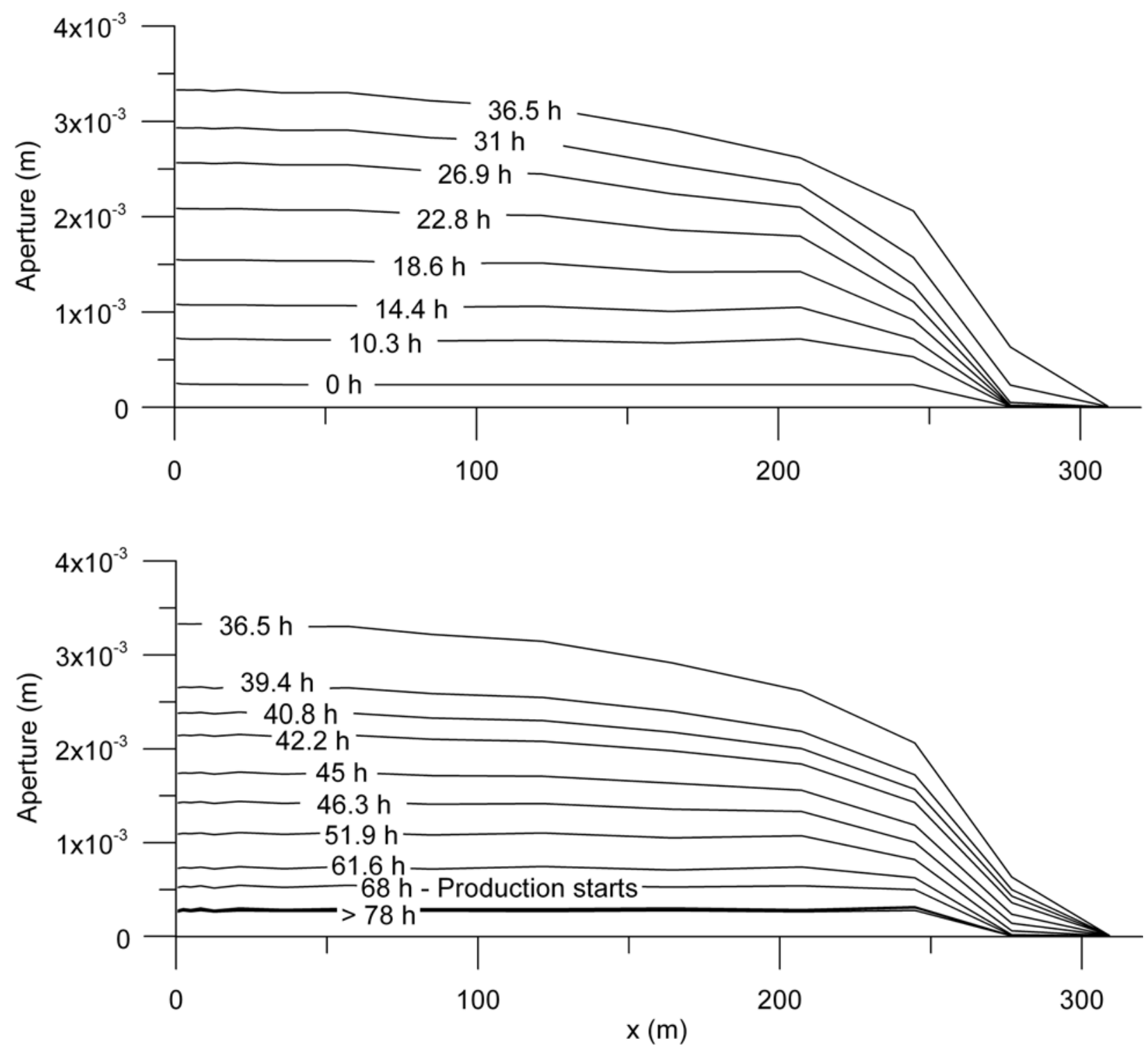

Fig. 15. February 2004 huff-puff test. Fracture deformation history for the injection (upper panel) and shut-in (lower panel) phase. The tip of the fracture is towards the right of the figure. 

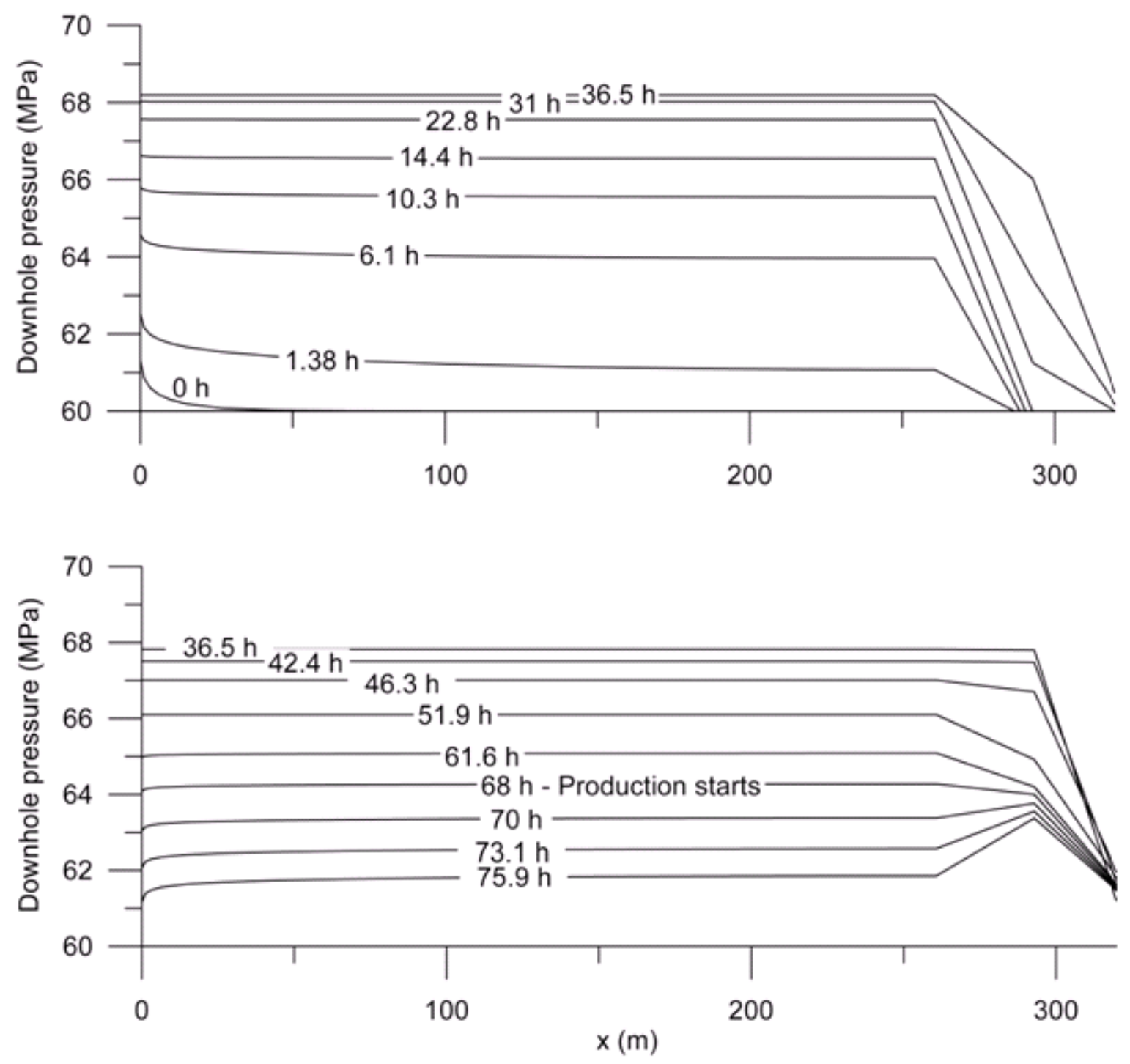

Fig. 16. February 2004 huff-puff test. History of the fluid pressure within the fracture for the injection (upper panel) and shut-in (lower panel) phase. The tip of the fracture is towards the right of the figure. 


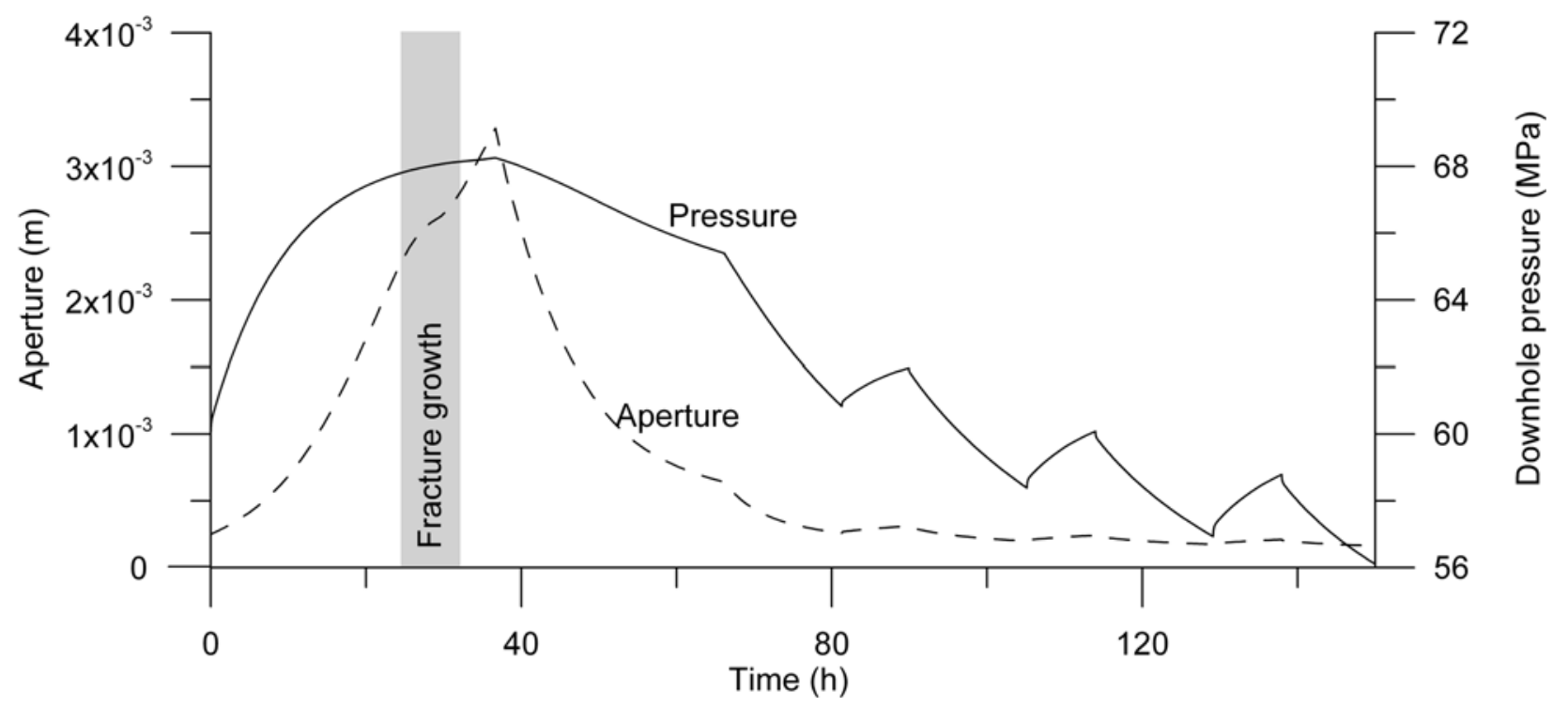

Fig. 17. February 2004 huff-puff test. Fracture aperture and fluid pressure history at $\mathrm{x}=40 \mathrm{~m}$. 